Numer ical and experi ment al i nvest i gat i ons on ther mal i nt er act $i$ on bet ween ther mal pl asma and sol id pol yner powders usi ng i nduct i on ther mal pl asma techni que

\begin{tabular}{|l|l|}
\hline 著者 & $\begin{array}{l}\text { Tanaka Yasunor i, Takeuchi Y. , Sakuyana T. , } \\
\text { Uesugi Yoshi hi ko, Kaneko S. , Okabe S. }\end{array}$ \\
\hline $\begin{array}{l}\text { j ournal or } \\
\text { publ i cat i on ti tl e }\end{array}$ & Journal of Physi cs D: Appl i ed Physi cs \\
\hline vol une & 41 \\
\hline nunber & 2 \\
\hline year & 2008-01-28 \\
\hline URL & ht tp: //hdl . handl e. net /2297/8945 \\
\hline
\end{tabular}




\title{
Numerical and experimental investigations on thermal interaction between thermal plasma and solid polymer powders using induction thermal plasma technique
}

\author{
Yasunori Tanaka $\nmid$, Y Takeuchi, T Sakuyama, Y Uesugi, \\ S Kaneko*, and S Okabe* \\ Division of Electrical Engineering and Computer Science, Kanazawa University, \\ Kakuma, Kanazawa 920-1192, Japan \\ * High Voltage \& Insulation Group, R\&D Center, The Tokyo Electric Power \\ Company, Inc., 4-1, Egasaki, Tsurumi, Yokohama 230-8510, Japan \\ E-mail: tanaka@ec.t.kanazawa-u.ac.jp
}

\begin{abstract}
Interaction between thermal plasma and polymer solid powders was investigated using inductively coupled thermal plasma (ICTP) technique. Interaction between thermal plasmas and polymers is extremely important, for example, for design of down-sized circuit breakers, because it fundamentally affects the interruption capability of the circuit breakers. The ICTP technique was used in the present work because it presents the advantages of no contamination and good repeatability. The polytetrafluoroethylene (PTFE), polymethylmethacrylate (PMMA), polyethylene $(\mathrm{PE})$, and polyoxymethylene (POM) were treated as polymer materials. Numerical modelling for injection of polymer solid powders into Ar thermal plasma was also made including thermal interactions between thermal plasmas and polymer powders. Results showed that PMMA-ablated vapour has a higher plasma-quenching efficiency than others; the polymer solid properties affect the plasma-quenching ability indirectly. Comparison of the calculated results to experimental results, showed good agreement from the viewpoints of the spatial distribution of ablated vapour concentration and the average solid particle velocity.
\end{abstract}

Submitted to: J. Phys. D: Appl. Phys.

† To whom correspondence should be addressed (tanaka@ec.t.kanazawa-u.ac.jp) 


\section{Introduction}

In a gas circuit breaker in a high-voltage electricity transmission system, a high-pressure electric arc plasma at pressures of $0.1-10 \mathrm{MPa}$ is formed between the electrodes during a large current interruption process. This arc plasma has a high temperature up to $30000 \mathrm{~K}$ around its core during kilo-ampere current flowing through the arc. Such the arc plasma can contact the nozzle in this process, and thereby induce ablation of the nozzle materials because of the arc plasma's high temperature. The temperature of the arc core can reach $30000 \mathrm{~K}$ at peak value of the electric current. Consequently, the arc plasma is inevitably contaminated with this ablated vapour, which markedly affects the interruption capability of the circuit breaker [1]-[14]. In gas circuit breakers, the nozzle is made mainly of polymer materials such as polytetrafluoroethylene (PTFE). On the other hand, in a mould case circuit breaker (MCCB) of a low-voltage electric distribution system, some polymer materials are used for the dielectric insulation case or for the quenching chamber wall. These polymer materials can also be ablated by the arc plasma inside the circuit breaker. In addition, recently, a polymer-ablation assisted type of the low-voltage MCCB has been developed [15], and a prototype of polymerablation assisted high-voltage gas circuit breaker has been tested [16]. These circuit breakers use polymer ablation to raise the pressure in the chamber, thereby producing strong gas flow or increasing the arc voltage. However, the effects of various polymerablated vapours themselves on arc plasma temperature and other physical parameters are still insufficiently understood. Interaction between thermal plasmas and polymer solid materials includes complex physical phenomena involving mass, momentum, and their mutual energy exchange. These interactions might produce a higher pressure rise in the chamber during polymer ablation processes, which creates a strong gas flow jet. They further cause thermal plasma quenching attributable to the heat consumption for melting and evaporation of polymers and also that attributable to the polymer-ablated vapour properties themselves.

We have already used inductively coupled thermal plasmas for a fundamental study of various gas or polymer-ablated vapour effect on the temperature of highpressure thermal plasmas, neglecting effects of pressure rise and gas flow jet [17][21]. The inductively coupled thermal plasma presents the crucial advantage of no contamination because it uses no electrode, as does either $\mathrm{DC}$ or $\mathrm{AC}$ arc plasma. It also has features of a good repeatability and controllability for experimental conditions. These advantages and features facilitate the investigation of the inherent characteristics of polymer-ablated vapours themselves on physical parameters of thermal plasmas such as the radiation intensity and the Ar excitation temperature [17, 19, 20]. In those experiments, polymer solid powders were actually injected into Ar induction thermal plasmas; then spectroscopic observations were carried out [19, 20]. Experimental results showed temperature decay, as revealed by injection of polymer powders, especially PMMA solid powder [19, 20]. However, this temperature decay is attributable to very complex phenomena including melting, evaporation, and vapour ejection from polymer 
powders into thermal plasma, which can again change the thermal plasma state. For that reason, it is difficult to investigate the interaction between thermal plasmas and polymer solid powders solely from the experimental results, which illustrates that a numerical simulation approach, in addition to an experimental approach, is essential to elucidate these complex phenomena.

In the present work, a model was produced of interactions between the thermal plasma and injected polymer solid powders. Using the model, the plasma-quenching efficiency of polymer-ablated vapours and the effect of polymer properties in solid and liquid phases were investigated from the viewpoint of the temperature decay of the thermal plasmas under identical electric input power conditions. To the authors' knowledge, few systematic investigations have been made into the interaction of thermal plasmas and polymer materials. This paper provides new contributions, especially related to the following points: (1) modelling of interaction between thermal plasmas and polymer powders considering the temperature gradient inside the polymer powders, (2) a comparison among PTFE, POM, PMMA, and PE properties in solid and liquid phases and their vapour thermodynamic and transport properties, (3) a prediction of temperature decay by injection of polymer solid powders, (4) a possible reason why PMMA injection causes the decay of the thermal plasma temperature, (5) a possible reason why $\mathrm{PE}$ injection causes the decay of the thermal plasma temperature. These results are helpful to elucidate thermal plasma quenching processes by polymer ablation phenomena.

\section{Polymers treated}

In this paper, the following four kinds of polymer materials are treated: polytetrafluoroethylene (PTFE), polymethylmethacrylate (PMMA), polyethylene (PE), and polyoxymethylene (POM). The first of them, PTFE, contains $\mathrm{C}$ and $\mathrm{F}$ atoms; its structural formula is $\left[-\mathrm{CF}_{2} \mathrm{CF}_{2^{-}}\right]_{n}$. It has an extremely low coefficient of friction, a nonreactive character, and high melting temperature of $618 \mathrm{~K}$ and evaporation temperature of $809 \mathrm{~K}$. This material is widely used as a nozzle material in high-voltage circuit breakers $[4,12,13,14]$. Both PMMA and POM include $\mathrm{C}, \mathrm{H}$, and $\mathrm{O}$ atoms. The structural formulae of PMMA and POM are, respectively, $\left[-\mathrm{C}_{5} \mathrm{H}_{8} \mathrm{O}_{2^{-}}\right]_{n}$, and $\left[-\mathrm{CH}_{2} \mathrm{O}-\right]_{n}$. The latter, POM, is used to make gears, bushings, and other mechanical parts. The former, PMMA, is known as a polymer material with a high transmissivity for visible light and with impact resistance. Finally, $\mathrm{PE}$ has only $\mathrm{C}$ and $\mathrm{H}$ atoms; its structural formula is $\left[-\mathrm{C}_{2} \mathrm{H}_{4^{-}}\right]_{n}$.

For this study, we used polymer powders to be introduced into thermal plasma. In the experiment, polymer solid powders with mean diameter of $300 \mu \mathrm{m}$ were used for all materials by screening powders. Figure 1 shows, as an example, a photographic image of PTFE solid powders used in the experiment. 


\section{Plasma torch configuration}

Figure 2 presents a schematic diagram of the plasma torch used in this work. The torch comprises two coaxial quartz tubes with $161 \mathrm{~mm}$ length. The inner and outer quartz tubes' internal diameters are, respectively, $82 \mathrm{~mm}$ and $100 \mathrm{~mm}$. Between the tubes, cooling water flows from bottom to the top side with a swirl to maintain the wall temperature at around $300 \mathrm{~K}$. An argon gas mixture is supplied as a sheath gas along the inner quartz tube wall with a swirl to prevent the plasma from contacting the inner quartz tube. Noble Ar is used as the work gas because the plasma can be sustained easily in the plasma torch and because Ar does not react chemically with polymer-ablated vapour. The plasma in the torch receives power from a three-turn coil by electromagnetic coupling. This coil is connected to a conventional high-power vacuum tube oscillator with a frequency of $1.67 \mathrm{MHz}$. At the top of the plasma torch, a water-cooled pipe is inserted along the centre axis of the plasma torch. From the centre of this pipe, polymer solid powders are fed with Ar centre carrier gas using a powder feeding system. For numerical simulation of the Ar thermal plasma with polymer powder injections, the calculation space was set to the two-dimensional cylindrical $r-z$ cross section of this plasma torch.

\section{Modelling}

\subsection{Assumptions}

The model is based on the PSI-Cell concept developed by Crowe et al [22]; it is an extension of the work by Proulx and co-workers [23, 24]. For modelling, the following conditions were assumed: (i) The plasma is in local thermodynamic equilibrium; consequently, all relevant temperatures such as the electron temperature, heavy particle temperature, and excitation temperature are mutually identical. In addition, chemical equilibrium conditions for all reactions are always established. (ii) The plasma is optically thin for wavelengths greater than $200 \mathrm{~nm}$. For wavelengths of less than 200 $\mathrm{nm}, 20 \%$ of the total emission coefficient is accounted for radiation loss to consider the effective light absorption $[19,25]$. (iii) The flow is steady, laminar, and axissymmetric, with negligible viscous dissipation. (iv) For injected particles, the particle-particle interactions are neglected. (v) The particle radius is much larger than the mean free path of plasma components. (vi) The particle is always spherical. (vii) Particle surface is uniformly heated from plasmas. Thus, ablation also uniformly occurs around the particle surface. (viii) Effects of electric charging on the particle are neglected. (ix) The rocket effect from ejected ablation vapour is neglected. (x) Polymer materials are ablated by the heat. Ablation attributable to the radiation power from the plasma is neglected. (xi) Deposition from polymer-ablated vapour onto the particle surface is neglected. These assumptions are roughly valid for a thermal plasma in this work.

One author (Y.T.) has already developed a two-temperature chemically nonequilibrium model for inductively coupled thermal plasmas, and discussed non- 
equilibrium effects in thermal plasmas in previous studies $[26,27,28]$. In those studies, it was found that non-equilibrium, especially chemically non-equilibrium, effects should be taken into account around the plasma torch wall for precise calculation. However, in the present work, we neglect non-equilibrium effects for simplicity because we specifically examine only the thermal effect of polymer ablation and ablation vapour itself on thermal plasmas involved in modelling. In addition, around the plasma torch axis, where powders are injected, the equilibrium is achieved easily [27].

\subsection{Governing equation for thermal plasma region}

Based on the assumptions described above, the thermal plasma is governed by the following equations.

Mass conservation.

$$
\frac{\partial(\rho u)}{\partial z}+\frac{1}{r} \frac{\partial(r \rho v)}{\partial r}=S_{\mathrm{p}}^{C}
$$

Momentum conservation.

Axial:

$$
\begin{aligned}
& \rho u \frac{\partial u}{\partial z}+\rho v \frac{\partial u}{\partial r} \\
& =-\frac{\partial p}{\partial z}+2 \frac{\partial}{\partial z}\left(\eta \frac{\partial u}{\partial z}\right) \\
& +\frac{1}{r} \frac{\partial}{\partial r}\left[\eta r\left(\frac{\partial u}{\partial r}+\frac{\partial v}{\partial z}\right)\right]+\mu_{0} \sigma \Re\left[\dot{E}_{\theta} \dot{H}_{r}^{*}\right]+S_{\mathrm{p}}^{M_{z}}
\end{aligned}
$$

Radial:

$$
\begin{aligned}
& \rho u \frac{\partial v}{\partial z}+\rho v \frac{\partial v}{\partial r} \\
& =-\frac{\partial p}{\partial r}+\frac{\partial}{\partial z}\left[\eta\left(\frac{\partial v}{\partial z}+\frac{\partial u}{\partial r}\right)\right] \\
& +\frac{2}{r} \frac{\partial}{\partial r}\left(\eta r \frac{\partial v}{\partial r}\right)-2 \eta \frac{v}{r^{2}}+\mu_{0} \sigma \Re\left[\dot{E}_{\theta} \dot{H}_{z}^{*}\right]+S_{\mathrm{p}}^{M_{r}}
\end{aligned}
$$

Swirl:

$$
\begin{aligned}
& \rho u \frac{\partial w}{\partial z}+\rho v \frac{\partial w}{\partial r} \\
& =\frac{\partial}{\partial z}\left(\eta \frac{\partial w}{\partial z}\right)+\frac{1}{r} \frac{\partial}{\partial r}\left(r \eta \frac{\partial w}{\partial r}\right) \\
& -\frac{\rho v w}{r}-\frac{w}{r} \frac{\partial r \eta}{\partial r}
\end{aligned}
$$

Energy conservation.

$$
\begin{aligned}
& \rho u \frac{\partial h}{\partial z}+\rho v \frac{\partial h}{\partial r} \\
& =\frac{\partial}{\partial z}\left(\frac{\lambda}{C_{\mathrm{p}}} \frac{\partial h}{\partial z}\right)+\frac{1}{r} \frac{\partial}{\partial r}\left(r \frac{\lambda}{C_{\mathrm{p}}} \frac{\partial h}{\partial r}\right) \\
& +\sigma\left|\dot{E}_{\theta}\right|^{2}-P_{\mathrm{rad}}-S_{\mathrm{p}}^{E}
\end{aligned}
$$


Polymer vapour concentration.

$$
\begin{aligned}
& \rho u \frac{\partial Y_{\mathrm{pol}}}{\partial z}+\rho v \frac{\partial Y_{\mathrm{pol}}}{\partial r} \\
& =\frac{\partial}{\partial z}\left(D_{\mathrm{pol}} \frac{\partial Y_{\mathrm{pol}}}{\partial z}\right)+\frac{1}{r} \frac{\partial}{\partial r}\left(r D_{\mathrm{pol}} \frac{\partial Y_{\mathrm{pol}}}{\partial r}\right)+S_{\mathrm{p}}^{C}
\end{aligned}
$$

Vector potential.

$$
\begin{aligned}
& \frac{\partial^{2} \dot{A}_{\theta}}{\partial z^{2}}+\frac{1}{r} \frac{\partial}{\partial r}\left(r \frac{\partial \dot{A}_{\theta}}{\partial r}\right)-\frac{\dot{A}_{\theta}}{r^{2}}=j \mu_{0} \sigma \omega \dot{A}_{\theta} \\
& \dot{H}_{z}=\frac{1}{\mu_{0}} \frac{1}{r} \frac{\partial}{\partial r}\left(r \dot{A}_{\theta}\right), \quad \dot{H}_{r}=-\frac{1}{\mu_{0}} \frac{\partial \dot{A}_{\theta}}{\partial z} \\
& \dot{E}_{\theta}=-j \omega \dot{A}_{\theta}
\end{aligned}
$$

In those equations, the following pertain. $r$ : radial position, $z$ : axial position, $u$ : axial flow velocity, $v$ : radial flow velocity, $\rho$ : mass density, $p$ : pressure, $\eta$ : viscosity, $h$ : enthalpy, $\lambda$ : thermal conductivity, $C_{\mathrm{p}}$ : specific heat at constant pressure, $\sigma$ : electrical conductivity, $P_{\text {rad }}$ : radiative loss, $Y_{\text {pol }}$ : mass fraction of polymer-ablated vapour, $D_{\mathrm{pol}}$ : effective diffusion coefficient of polymer-ablated vapour against $\mathrm{Ar}, \mu_{0}$ : permeability of vacuum, $\dot{A}_{\theta}$ : phasor of the vector potential, $\omega$ : frequency of the coil current, $\dot{E}_{\theta}$ : phasor of the electric field strength, $\dot{H}_{z}, \dot{H}_{r}$ : phasors of axial and radial components, of the magnetic field strength, respectively, $j$ : complex factor $\left(j^{2}=-1\right)$. The vector potential $\vec{A}(r, z, t)$ has only an azimuthal component $\vec{A}(r, z, t)=\left(0, \sqrt{2} \dot{A}_{\theta} e^{j \omega t}, 0\right)$, where the phasor $\dot{A}_{\theta}$ has a real and an imaginary part like $\dot{A}_{\theta}=A_{\theta R}+j A_{\theta I}$. The magnitudes of the phasors including $\dot{A}_{\theta}, \dot{E}_{\theta}, \dot{H}_{z}$ and $\dot{H}_{r}$ are defined as the root mean square values. The asterisks $*$ in equations (2) and (3) indicate the conjugate, and a symbol $\Re$ is the real part of the phasor. The quantities $S_{\mathrm{p}}^{C}, S_{\mathrm{p}}^{M_{z}}, S_{\mathrm{p}}^{M_{r}}$, and $S_{\mathrm{p}}^{E}$ indicate source terms by the translation quantities from ablated vapour. These quantities are described later.

\subsection{Dynamics and heating of particles injected in the gas flow}

On the assumption that the only forces affecting an individual particle are drag and gravity, the momentum equation for a single particle injected vertically downward into the plasma can be expressed as

$$
\begin{aligned}
\frac{d u_{\mathrm{p}}}{d t} & =-\frac{3}{4} C_{\mathrm{D}}\left(u_{\mathrm{p}}-u\right) U_{\mathrm{R}}\left(\frac{\rho}{\rho_{\mathrm{p}} d_{\mathrm{p}}}\right)+g \\
\frac{d v_{\mathrm{p}}}{d t} & =-\frac{3}{4} C_{\mathrm{D}}\left(v_{\mathrm{p}}-v\right) U_{\mathrm{R}}\left(\frac{\rho}{\rho_{\mathrm{p}} d_{\mathrm{p}}}\right) \\
U_{\mathrm{R}} & =\sqrt{\left(u_{\mathrm{p}}-u\right)^{2}+\left(v_{\mathrm{p}}-v\right)^{2}}
\end{aligned}
$$

where $U_{\mathrm{R}}$ is the relative velocity between the particle and plasma, $C_{\mathrm{D}}$ is the drag coefficient, $g$ is the gravitational acceleration, $u_{\mathrm{p}}$ is the axial velocity of the particle, $v_{\mathrm{p}}$ is the radial velocity of the particle, $\rho_{\mathrm{p}}$ is the mass density of the particle in solid and 
liquid phases, and $d_{\mathrm{p}}$ is the particle diameter. In addition, the directions of particles at the outlet of the powder feeding pipe were set randomly to three angle directions to simulate reflections of particles with the pipe inner wall [21].

The energy conservation equation for particles is expressed with consideration of the thermal conduction inside the particle. We initially divided the particle into 20 shells to treat the temperature gradient inside the particle. In addition, we defined the temperature $T_{\mathrm{p}}(r, t)$ and the liquid fraction $\chi(r, t)$ of each shell which are dependent on the radial position $r$ and the time $t$. In this case, the energy conservation equation is expressed as follows.

Inner shells $\left(0<r \leq d_{\mathrm{p}-1} / 2\right)$ :

$$
\begin{aligned}
& \rho_{\mathrm{p}} C_{\mathrm{pp}} \frac{\partial T_{\mathrm{p}}(r, t)}{\partial t}=\frac{1}{r^{2}} \frac{\partial}{\partial r}\left(r^{2} \lambda_{\mathrm{p}} \frac{\partial T_{\mathrm{p}}(r, t)}{\partial r}\right) \\
& \left(T_{\mathrm{p}}(r, t)<T_{\mathrm{m}}, T_{\mathrm{m}}<T_{\mathrm{p}}(r, t)<T_{\mathrm{b}}\right) \\
& \rho_{\mathrm{p}} H_{\mathrm{m}} \frac{\partial \chi(r, t)}{\partial t}=\frac{1}{r^{2}} \frac{\partial}{\partial r}\left(r^{2} \lambda_{\mathrm{p}} \frac{\partial T_{\mathrm{p}}(r, t)}{\partial r}\right) \quad\left(T_{\mathrm{p}}(r, t)=T_{\mathrm{m}}\right)
\end{aligned}
$$

Outer shell $\left(r>d_{\mathrm{p}-1} / 2\right)$ :

$$
\begin{aligned}
& \frac{1}{6} \pi\left(d_{\mathrm{p}}^{3}-d_{\mathrm{p}-1}^{3}\right) \cdot \rho_{\mathrm{p}} C_{\mathrm{pp}} \frac{\partial T_{\mathrm{p}}\left(r_{\text {out }}, t\right)}{\partial t}=Q \\
& \frac{1}{6} \pi\left(d_{\mathrm{p}}^{3}-d_{\mathrm{p}-1}^{3}\right) \cdot \rho_{\mathrm{p}} H_{\mathrm{m}} \frac{\partial \chi\left(r_{\text {out }}, t\right)}{\partial t}=Q \quad\left(T_{\mathrm{p}}\left(r_{\text {out }}, t\right)=T_{\mathrm{m}}\right) \\
& \frac{\pi d_{\mathrm{p}-1}^{2}}{2} \cdot \rho_{\mathrm{p}} H_{\mathrm{v}} \frac{\partial\left(d_{\mathrm{p}}\right)}{\partial t}=Q \quad\left(T_{\mathrm{p}}\left(r_{\text {out }}, t\right)=T_{\mathrm{b}}\right) \\
& Q=-\left.\pi d_{\mathrm{p}-1}^{2} \lambda_{\mathrm{p}} \frac{\partial T_{\mathrm{p}}}{\partial r}\right|_{\left.\left.r=d_{\mathrm{p}-1 / 2}, t\right)<T_{\mathrm{b}}\right)}+\pi d_{\mathrm{p}}^{2} h_{c}\left(T-T_{\mathrm{p}}\left(r_{\text {out }}, t\right)\right) \\
& -\pi d_{\mathrm{p}}^{2} \sigma_{\mathrm{s}} \epsilon\left(T_{\mathrm{p}}\left(r_{\text {out }}, t\right)^{4}-T_{\mathrm{a}}^{4}\right)
\end{aligned}
$$

In those equations, the following variables are used. Q: the heat at the outer shell, $T_{\mathrm{p}}(r, t)$ : the shell temperature inside the particle, $T_{\mathrm{m}}$ : the polymer melting temperature, $T_{\mathrm{b}}$ : the polymer boiling/thermal decomposition temperature, $T$ : the plasma temperature, $\epsilon$ : the particle surface emissivity, $T_{\mathrm{a}}$ : the ambient temperature, $\sigma_{\mathrm{s}}$ : Stefan-Boltzmann coefficient, $C_{\mathrm{pp}}$ : the specific heat of the particle in solid or liquid phases, $\rho_{\mathrm{p}}$ : mass density of the polymer particle, $d_{\mathrm{p}-1}$ : the outer shell's inner diameter, $\lambda_{\mathrm{p}}$ : the thermal conductivity of the polymer, $H_{\mathrm{m}}$ : the latent heat for melting, $H_{\mathrm{v}}$ : the latent heat for evaporation, $\chi(r, t)$ : liquid fraction of the shell, $h_{\mathrm{c}}$ : the heat transfer coefficient between thermal plasma and polymer surface, $r_{\text {out }}$ : the radial position of the control volume of the outer shell, which is defined as $r_{\mathrm{out}}=\frac{1}{4}\left(d_{\mathrm{p}}+d_{\mathrm{p}-1}\right)$. Equations (13)-(18) were discritized by the control volume method, and solved by Euler explicit method considering time constraint for stable calculation.

Figure 3 shows the concept and the definition of parameters in this calculation. Inside the particle, thermal conduction due to the radial gradient of the temperature 
were taken into account for any temperature range as indicated in equations (13) and (14). When the temperature $T_{\mathrm{p}}(r, t)$ at a point inside the particle is not equal to the melting temperature $T_{\mathrm{m}}$, the temperature can be changed according to equation (13). If the temperature $T_{\mathrm{p}}(r, t)$ is the melting temperature $T_{\mathrm{m}}$, the melting phenomenon occurs to change the liquid fraction $\chi(r, t)$ as indicated in equation (14).

On the other hand, at the outer shell, more complex phenomena have to be considered including the thermal conduction to the inner side of the particle, the heat transfer from the surrounding plasma, the radiation loss from the surface of the particle, and the evaporation. Equation (18) indicates the heat $Q$ at the outer shell, in which the first term on right hand side is the thermal conduction to the inner direction of the particle, the second term is the heat transfer from the surrounding plasma, and the third term is the radiation loss from the surface of the particle. When the temperature $T_{\mathrm{p}}\left(r_{\mathrm{out}}, t\right)$ at the outer shell of the particle is not the melting temperature $T_{\mathrm{m}}$ nor the boiling temperature $T_{\mathrm{b}}$, the temperature can be changed according to equation (15). If the temperature $T_{\mathrm{p}}\left(r_{\mathrm{out}}, t\right)$ is the melting temperature $T_{\mathrm{m}}$, the melting phenomenon occurs to change the liquid fraction $\chi\left(r_{\text {out }}, t\right)$ as indicated in equation (16). When the temperature

$T_{\mathrm{p}}\left(r_{\mathrm{out}}, t\right)$ reaches to the boiling temperature $T_{\mathrm{b}}$, evaporation occurs involving a reduction in diameter of the particle as equation (17). After the outer shell is completely evaporated according to equation (17), the inner shell that previously neighbours on the outer shell was newly set as the new outer shell. To simulate melting phenomena, the small time step of $5 \mu$ s was chosen.

The quantities $C_{\mathrm{D}}$ and $h_{\mathrm{c}}$ were given as a function of Reynolds number [23]. We neglected the size effect occurring for conditions in which the injected polymer particle diameter is comparable to the mean free path of the particle.

\subsection{Particle source terms}

Particle source terms were computed at each cell using the PSI cell concept developed by Crowe et al [22] and by Proulx et al [23]. Although the details have been described in the relevant literature $[22,23,24]$, we briefly mention them to aid recall.

In the PSI cell approach, the polymer particles are regarded as sources of mass, momentum and energy of plasma equations. Let $N_{t}^{0}$ be the number of particles injected per unit time; $n_{d}$ is the particle size distribution, and $n_{r}$ represents the fraction of $N_{t}^{0}$ injected at each point over the torch central inlet. The number of particles per unit time travelling along the trajectory $(l, k)$ corresponding to a particle diameter $d_{l}$ injected at point $r_{k}$ is expressed as the following.

$$
N^{l, k}=n_{d_{l}} n_{r_{k}} N_{\mathrm{t}}^{0}
$$

The particle concentration $n_{r}$ in the inlet was assumed to be uniform in this calculation. On the other hand, for the sake of computation, the powder input position is set to five points at radial positions of $0.3,0.6,0.9,1.2$, and $1.5 \mathrm{~mm}$. In the actual experimental condition, the injected powder consists of particles of various size. For the computation, we assumed that the powder consists of seven particles of discrete 
diameter. A particle with a powder average diameter of $300 \mu \mathrm{m}$ has a fraction of $60 \%$. Table 1 shows the assumed Gaussian distribution fraction of particles. The distribution fraction of the other particles was also assumed to decrease with increasing deviation of its diameter from the powder average diameter. Those conditions imply 35 possible particle trajectories. The particle injection velocity was assumed to be equal to the carrier gas velocity. The source term in the continuity equation, $S_{\mathrm{p}}^{C}$, is the net efflux rate of the particle mass in a computational cell (control volume). Based on the assumption that the particles are spherical, the efflux rate of the particle mass attributable to the particle trajectory $(l, k)$ which traverses a given cell $(i, j)$ is:

$$
S_{\mathrm{p}, i j}^{C(l, k)}=\frac{1}{6} \pi \rho_{\mathrm{p}} N_{i j}^{(l, k)}\left(d_{i j, \text { in }}^{3}-d_{i j, \text { out }}^{3}\right) .
$$

The net efflux rate of particle mass is obtained by summing over all particle trajectories which traverse a given cell:

$$
S_{\mathrm{p}, i j}^{C}=\sum_{l} \sum_{k} S_{\mathrm{p}, i j}^{C(l, k)} .
$$

The momentum source terms are evaluated in the same fashion as the particle mass source terms. In this case, the efflux rate of particle momentum attributable to the particle trajectory $(l, k)$ traversing a given cell $(i, j)$ is the following. The quantities $S_{\mathrm{p}}^{M_{z}}$ and $S_{\mathrm{p}}^{M_{z}}$ are described as

$$
\begin{aligned}
& S_{\mathrm{p}, i j}^{M_{z}(l, k)}=\frac{1}{6} \pi \rho_{\mathrm{p}} N_{i j}^{(l, k)}\left(u_{i j, \text { in }} d_{i j, \text { in }}^{3}-u_{i j, \text { out }} d_{i j, \text { out }}^{3}\right) \\
& S_{\mathrm{p}, i j}^{M_{r}(l, k)}=\frac{1}{6} \pi \rho_{\mathrm{p}} N_{i j}^{(l, k)}\left(v_{i j, \text { in }} d_{i j, \text { in }}^{3}-v_{i j, \text { out }} d_{i j, \text { out }}^{3}\right),
\end{aligned}
$$

and the corresponding momentum source terms are

$$
\begin{aligned}
& S_{\mathrm{p}, i j}^{M_{z}}=\sum_{l} \sum_{k} S_{\mathrm{p}, i j}^{M_{z}(l, k)} \\
& S_{\mathrm{p}, i j}^{M_{r}}=\sum_{l} \sum_{k} S_{\mathrm{p}, i j}^{M_{r}(l, k)} .
\end{aligned}
$$

The energy source term includes the heat given to the particles $Q_{\mathrm{p}, i j}^{(l, k)}$, and superheat to bring the particle vapours into thermal equilibrium with the plasma $Q_{\mathrm{v}, i j}^{(l, k)}$.

The quantity $S_{\mathrm{p}}^{E}$ is expressed using $Q_{\mathrm{p}, i j}^{(l, k)}$ and $Q_{\mathrm{v}, i j}^{(l, k)}$ as follows.

$$
\begin{aligned}
& Q_{\mathrm{p}, i j}^{(l, k)}=\int_{\tau_{\text {in }}}^{\tau_{\text {out }}} \pi d_{\mathrm{p}}^{2} h_{c}\left[T_{i j}-T_{\mathrm{p}, i j}^{(l, k)}\right] d t \\
& Q_{\mathrm{v}, i j}^{(l, k)}=\int_{\tau_{\text {in }}}^{\tau_{\text {out }}} \frac{\pi}{2} d_{\mathrm{p}}^{2} \rho_{\mathrm{p}}\left(\frac{d d_{\mathrm{p}}}{d t}\right) C_{\mathrm{pp}}\left[T_{i j}-T_{\mathrm{p}, i j}^{(l, k)}\right] d t \\
& S_{\mathrm{p}, i j}^{E}=\sum_{l} \sum_{k} N_{i j}^{(l, k)}\left[Q_{\mathrm{p}, i j}^{(l, k)}+Q_{\mathrm{v}, i j}^{(l, k)}\right]
\end{aligned}
$$




\subsection{Thermodynamic and transport properties of polymer-ablated vapour}

Thermodynamic and transport properties of polymer-ablated vapour were calculated under the local thermodynamic equilibrium assumption as follows. First, the equilibrium composition of Ar-polymer-ablated vapour at atmospheric pressure was calculated as a function of the temperature from 300 to $30000 \mathrm{~K}$ and the polymer-ablated vapour concentration from 0 to $100 \%$ [19]. In the calculation of the equilibrium composition, the following particles were taken into account for Ar-PTFE ablated vapour including $\mathrm{C}$ and $\mathrm{F}$ atoms: $\mathrm{C}_{2} \mathrm{~F}_{6}, \mathrm{C}_{2} \mathrm{~F}_{4}, \mathrm{C}_{2} \mathrm{~F}_{2}, \mathrm{CF}_{4}, \mathrm{CF}_{3}, \mathrm{CF}_{2}, \mathrm{CF}, \mathrm{C}_{5}, \mathrm{C}_{4}, \mathrm{C}_{3}, \mathrm{C}_{2}, \mathrm{~F}_{2}, \mathrm{C}, \mathrm{F}, \mathrm{CF}_{3}^{+}$, $\mathrm{CF}_{2}^{+}, \mathrm{C}_{2}^{+}, \mathrm{C}_{2}^{-}, \mathrm{C}^{+}, \mathrm{C}^{2+}, \mathrm{C}^{-}, \mathrm{F}_{2}^{+}, \mathrm{F}^{+}, \mathrm{F}^{2+}, \mathrm{F}^{-} \mathrm{Ar}, \mathrm{Ar}^{+}, \mathrm{Ar}^{2+}$, and the electron. For POM and PMMA ablated vapours including $\mathrm{C}, \mathrm{H}$, and $\mathrm{O}$ atoms, we considered the following particles: $\mathrm{C}_{2} \mathrm{H}_{4} \mathrm{O}, \mathrm{CH}_{2} \mathrm{O}, \mathrm{CHO}, \mathrm{C}_{2} \mathrm{H}_{4}, \mathrm{C}_{2} \mathrm{H}_{2}, \mathrm{C}_{2} \mathrm{H}, \mathrm{CH}_{4}, \mathrm{CH}_{3}, \mathrm{CH}_{2}, \mathrm{CH}, \mathrm{C}_{3} \mathrm{O}_{2}, \mathrm{C}_{2} \mathrm{O}$, $\mathrm{CO}_{2}, \mathrm{CO}, \mathrm{C}_{5}, \mathrm{C}_{4}, \mathrm{C}_{3}, \mathrm{C}_{2}, \mathrm{H}_{2} \mathrm{O}, \mathrm{HO}_{2}, \mathrm{OH}, \mathrm{O}_{3}, \mathrm{O}_{2}, \mathrm{H}_{2}, \mathrm{H}, \mathrm{C}, \mathrm{O}, \mathrm{Ar}, \mathrm{CHO}^{+}, \mathrm{CH}^{+}, \mathrm{CO}_{2}^{-}$ $\mathrm{C}_{2}^{-}, \mathrm{C}^{+}, \mathrm{C}^{2+}, \mathrm{C}^{-}, \mathrm{H}_{2}^{+}, \mathrm{H}_{2}^{-}, \mathrm{OH}^{+}, \mathrm{OH}^{-}, \mathrm{H}^{+}, \mathrm{H}^{-}, \mathrm{O}_{2}^{+}, \mathrm{O}_{2}^{-}, \mathrm{O}^{+}, \mathrm{O}^{2+}, \mathrm{O}^{-}, \mathrm{Ar}^{+}, \mathrm{Ar}^{2+}$, and the electron. On the other hand, for the $\mathrm{PE}$ ablated vapour, the same particles as those of the PMMA and POM were accounted for, except for particles containing $\mathrm{O}$ atoms. By minimizing the Gibbs' free energy of the system of Ar-polymer-ablated vapour, the equilibrium compositions were obtained.

Figure 4 shows the calculated equilibrium composition of $50 \%$ Ar- $50 \%$ PTFE ablated vapour at a pressure of $0.1 \mathrm{MPa}$, as an example. At temperatures of $300-1000 \mathrm{~K}$, the dominant species are $\mathrm{Ar}, \mathrm{CF}_{4}, \mathrm{C}_{2} \mathrm{~F}_{6}$, and $\mathrm{C}_{5}$. However, $\mathrm{C}_{2} \mathrm{~F}_{6}$ is dissociated by the temperature increase from 300 to $1000 \mathrm{~K}$. At temperatures of $1000-3000 \mathrm{~K}, \mathrm{CF}_{2}, \mathrm{C}_{3}$, $\mathrm{CF}_{3}$, and $\mathrm{F}$ are created to be dominant species. When increasing the temperature from 3000 to $10000 \mathrm{~K}$, the electron density is elevated mainly by ionization of C. For other polymer materials, the equilibrium compositions are calculated similarly.

Using the calculated equilibrium composition, we computed the thermodynamic properties like enthalpy $h$, specific heat $C_{\mathrm{p}}$, and mass density $\rho$. Transport properties such as the electrical conductivity $\sigma$, the thermal conductivity $\lambda$, and the viscosity $\eta$ were calculated based on the first-order approximation of the Chapman-Enskog method [29]-[32] using the calculated equilibrium composition and the collision integrals between components of Ar-polymer-ablated vapour. The first-order approximation of the Chapman-Enskog method is roughly sufficient if the temperature is lower than 10000 K. The emission coefficients were calculated for all monatomic lines and the continuum including bremsstrahlung and recombination radiation by classical theory [19, 29, 32].

Figure 5 shows the calculated specific heat $C_{\mathrm{p}}$ of $90 \% \mathrm{Ar}-10 \%$ polymer-ablated vapour as a function of temperature for different polymer materials as an example. The specific heat $C_{\mathrm{p}}$ has inherent peaks at certain temperatures. These peaks are well known to be attributable to reactions including dissociation/association reactions, and ionization/recombination reactions at the relevant temperatures. For example, the specific heat $C_{\mathrm{p}}$ of PMMA ablated vapours has peaks at 1200, 3500,4900,6600, and $14700 \mathrm{~K}$. These peaks are the results of respective reactions $2 \mathrm{CH}_{4} \leftrightarrow \mathrm{C}_{2} \mathrm{H}_{2}+3 \mathrm{H}_{2}$ around $1200 \mathrm{~K}, \mathrm{C}_{2} \mathrm{H} \leftrightarrow 2 \mathrm{C}+\mathrm{H}$ around $3500 \mathrm{~K}, \mathrm{CO} \leftrightarrow \mathrm{C}+\mathrm{O}$ and $\mathrm{C} \leftrightarrow \mathrm{C}^{+}+\mathrm{e}$ around 
$6600 \mathrm{~K}, \mathrm{Ar} \leftrightarrow \mathrm{Ar}^{+}+$e around $14700 \mathrm{~K}$. The calculated results for thermodynamic properties agree well with data from the relevant literature [2].

The effective diffusion coefficient of polymer vapour $D_{\mathrm{pol}}$ was calculated from the following effective binary diffusion coefficient [27]:

$$
D_{\mathrm{pol}}=\frac{3}{8} \frac{k T}{p}\left[\frac{\pi k T\left(m_{\mathrm{Ar}}+m_{\mathrm{pol}}\right)}{2 m_{\mathrm{Ar}} m_{\mathrm{pol}}}\right]^{\frac{1}{2}} \frac{1}{Q_{\mathrm{Ar}-\mathrm{pol}}^{(1)}}
$$

where $k$ is the Boltzmann constant, $m_{\mathrm{Ar}}$ is the mass of Ar atom, $m_{\mathrm{pol}}$ is the effective mass of polymer vapour depending on particle composition of polymer vapour, $Q_{\mathrm{Ar}-\mathrm{pol}}^{(1)}$ is the effective momentum transfer cross section between Ar and polymer vapour, which was estimated from the hard-sphere method.

\subsection{Properties of polymer solid powders}

The thermal properties of these polymer solid powders, including the melting and boiling/thermal decomposition temperatures, the latent heats of melting and boiling/thermal decomposition, and the specific heat, were actually measured using thermogravimetry - differential thermal analysis (TG-DTA) and the differential scanning calorimetry (DSC) method. On the other hand, typical values of mass density, thermal conductivity and emissivity for polymer materials were obtained or estimated from the polymer database [33]. Table 2 summarizes the thermal properties of polymer powders used in this work. As this table shows, PE has the lowest melting temperature and lowest latent heat for boiling. On the other hand, PTFE has the highest melting and evaporation temperatures. The present calculations used these values.

\subsection{Calculation condition}

Calculation conditions were set as identical to experimental conditions to compare the calculation results with the experimental results later. Argon gas was supplied as a sheath gas, with a fixed gas flow rate of $100 \mathrm{slpm}$ (100 standard litres per minute = $\left.1.67 \times 10^{-3} \mathrm{~m}^{3} \mathrm{~s}^{-1}\right)$. The swirl angle of the sheath gas flow was previously measured and the measured angle was set in the calculation. Pressure inside the plasma torch was maintained at atmospheric pressure of $101325 \mathrm{~Pa}$. Polymer solid powders were fed from a water-cooled copper pipe together with the Ar carrier gas. The Ar carrier gas flow rate was $1 \mathrm{slpm}$; the powder feed rate was measured as about $1 \mathrm{~g} \mathrm{~min}^{-1}(=1.67 \times$ $10^{-5} \mathrm{~kg} \mathrm{~s}^{-1}$ ). The input power at the plate terminal of the vacuum tube oscillator was set to $50 \mathrm{~kW}$ for the experiment. In this case, the active input power into the plasma is about $30 \mathrm{~kW}$ because of the estimated energy conversion efficiency of the vacuum tube oscillator. Therefore, input power of $30 \mathrm{~kW}$ to the plasma was set in the calculation. We assumed the Gaussian distribution of particle diameter, as described previously. The particle diameter distribution only slightly affects the temperature distribution of plasmas [21]. 
The governing equations are solved using the SIMPLER method, according to the description of Patankar[34].

\section{Calculation results}

\subsection{Temperature and diameter variations of injected solid polymer powders}

Figures $6(a)-6(c)$ illustrate the radial temperature distribution inside a moving test PTFE particle injected into Ar thermal plasmas. Panels respectively correspond to the temperature distributions at $(a) t_{\mathrm{p}}=5 \mathrm{~ms}$ and $z_{\mathrm{p}}=9.20 \mathrm{~mm},(b) t_{\mathrm{p}}=25 \mathrm{~ms}$ and $z_{\mathrm{p}}=43.76$ $\mathrm{mm}$, and $(c) t_{\mathrm{p}}=30 \mathrm{~ms}$ and $z_{\mathrm{p}}=49.45 \mathrm{~mm}$, where $t_{\mathrm{p}}$ is the time after injection of the test particle, and $z_{\mathrm{p}}$ is the axial position of the test particle in the plasma torch. In the water-cooled pipe region, i.e. axial positions of $z_{\mathrm{p}}=0-32 \mathrm{~mm}$, the injected particle is not heated. For that reason, the temperature inside the whole particle is $300 \mathrm{~K}$, and the radius remains $150 \mu \mathrm{m}$, as shown in figure 6(a). However, once the particle exits the water-cooled pipe, the particle is heated rapidly. At $25 \mathrm{~ms}$ after injection, the particle reaches axial position $z_{\mathrm{p}}=43.76 \mathrm{~mm}$ in reference to the plasma torch. In this case, the outer shell temperature increases to the thermal decomposition temperature. Then the particle diameter starts decreasing because of thermal decomposition, as shown in figure $6(b)$. At $30 \mathrm{~ms}$ after injection, the radius of a test particle decreases to $100 \mu \mathrm{m}$, as shown in figure $6(c)$.

More detailed temperature variation at each shell inside the particle, and temporal variation in the particle diameter are also apparent in figure 7. The PTFE particle's outer shell temperature increases rapidly after particle ejection to the high-temperature plasma region from the axial position $z_{\mathrm{p}}=35 \mathrm{~mm}$. When the temperature reaches the melting temperature of the PTFE materials, i.e. $618 \mathrm{~K}$, melting occurs. In this case, the particle's outer shell maintains a constant temperature of 618 K. Simultaneously, the liquid fraction at the outer shell is increased during melting. During these processes, the heat is transported from the outer side to the inner side of the particle by thermal conduction to increase the inside temperature of the particle. If the liquid fraction of each shell reaches unity, the temperature of the shell is again increased; then the temperature reaches to the evaporation/thermal decomposition temperature of $809 \mathrm{~K}$. The particle moves to position at $z_{\mathrm{p}}=42.5 \mathrm{~mm}$ when this evaporation process occurs. At the evaporation temperature, the particle diameter decreases, as designated by a thick curve in figure 7 . At $z=53 \mathrm{~mm}$, the evaporation is almost completed. It is also apparent in the calculation that complete evaporation is achieved up to the axial position around $60 \mathrm{~mm}$ for PMMA, PE, and POM polymer powders.

\subsection{Temperature decay of Ar thermal plasmas by polymer solid powder injection}

Injection of polymer solid powders decreases the temperature of thermal plasmas because the powders consume energy from the thermal plasma for their melting and ablation. Furthermore, the ablated vapour influences the thermal plasma temperature field. 
Figure 8(a) shows the temperature distribution of an Ar induction thermal plasma with only Ar sheath gas, and figure 8(b) is that with Ar sheath gas and Ar carrier centre gas. In addition, figure 8(c) represents that with Ar carrier centre gas and PTFE powder injection.

The Ar thermal plasma has a high temperature of about $9000 \mathrm{~K}$ inside the plasma torch in figure 8(a). Injection of the Ar carrier centre gas decreases the temperature just under the water-cooled pipe, as portrayed in figure 8(b). Additional PTFE solid powder injection causes a further temperature decay of the Ar thermal plasma immediately under the pipe and also around the plasma torch axis, as shown in figure 8(c), because PTFE absorbs heat to be melted and evaporated, and the PTFE ablated vapour itself cools thermal plasma around the evaporation region [27].

Figure 9 shows the temperature distribution of the thermal plasma in cases of PTFE, PMMA, PE, and POM solid powder injections. As portrayed in the figure, the PE and PMMA solid powder injections produce a more remarkable temperature decay around the plasma torch axis than those of PTFE and POM. The POM powder injection engenders a more severe temperature decay than that of PTFE powder. For ready comparison with different polymer materials, radial temperature distributions of the plasma at $z=95 \mathrm{~mm}$, i.e. at $10 \mathrm{~mm}$ below the coil end region, are shown for different polymer material injections in figure 10. The Ar centre carrier gas injection does not greatly decrease the temperature around the axis of the plasma torch at this axial position. Injection of polymer solid powders causes a nearly $2000 \mathrm{~K}$ temperature decrease for any kind of polymer powder. The PMMA and PE injection decays the temperature on the plasma torch axis more than the others. This temperature decay by $\mathrm{PE}$ injection arises from the fact that PE has lower melting and boiling temperatures, which facilitates its ablation. On the other hand, PMMA vapour itself has a higher plasma-quenching efficiency than the others. As a result, the temperature of thermal plasma is decreased. Further discussion about the above temperature decay will be presented in a later section.

The amount of ablated vapour also influences the temperature decay of the Ar thermal plasmas. Figure 11 shows the spatial distributions of contaminated polymer vapour mass fraction $Y_{\text {pol }}$ in the Ar thermal plasma. Contours for the polymer vapour mass fraction are plotted on a logarithmic scale. The polymer vapour mass fraction is still low immediately under the water-cooled pipe, i.e. around the axial position of $z=32-48 \mathrm{~mm}$ around the plasma torch axis. In this region, polymer solid powders are merely heated and then melted. Downstream of such a region, a higher polymer vapour mass fraction region exists around the axial position of $z=50-70 \mathrm{~mm}$ around the plasma torch axis. In that region, the polymer solid powder is ablated to produce polymerablated vapour. That polymer-ablated vapour is transported to the downstream region of the plasma torch along the torch axis (around axial position $z=70-160 \mathrm{~mm}$ ), mainly by convection. In addition, a high polymer vapour mass fraction region exists on the upper side of the plasma torch around the outside of the water-cooled pipe. The ablated vapour is transported to the upper side of the plasma torch because of the convection 
attributable to a vortex produced at the upper side of the plasma torch, as indicated in figure 12, in which the stream line is indicated. Such a vortex is apparent for cases of any polymer solid powder injection. The gas flow field is independent of the kind of injected polymer. It is apparent again from figure 11 that the cases of PE and PMMA have higher mass fractions of the polymer vapours. This result shows that $\mathrm{PE}$ and PMMA have higher plasma-quenching efficiencies in terms of the temperature decay of thermal plasmas.

\subsection{Total amount of mass and energy loss for polymer powder ablation}

The total amount of mass and energy loss for polymer powder ablation are also essential to study the efficiency on temperature decay of thermal plasmas. The total amount mass $M_{\text {tot }}$ and energy loss $W_{\text {tot }}$ for polymer powder ablation in the thermal plasmas can be calculated by

$$
\begin{aligned}
& M_{\mathrm{tot}}=\iint S_{\mathrm{p}}^{C} 2 \pi r d r d z, \\
& W_{\mathrm{tot}}=\iint S_{\mathrm{p}}^{E} 2 \pi r d r d z .
\end{aligned}
$$

Table 3 compares the total amount of mass $M_{\text {tot }}$ and energy loss $W_{\text {tot }}$ for different polymer powder ablation at a powder feed rate of $1 \mathrm{~g} \mathrm{~min}^{-1}$. As seen in this table, there is only a slight difference in the total amount of mass $M_{\text {tot }}$ for ablation for different polymer powders. On the other hand, the total amounts of energy loss $W_{\text {tot }}$ for PE and POM are larger than PTFE and PMMA. This seems that more energy is necessary to ablate PE and POM powders.

In spite of this fact, PMMA injection causes a large temperature decay of thermal plasmas than PTFE and POM as seen in figures 9-10 in the previous section. This fact means that in case of PMMA powder injection, PMMA ablated vapor itself has a high plasma-quenching efficiency, rather than energy loss for its ablation. In case of PE powder injection, on the other hand, the energy loss for its ablation affects temperature decay of thermal plasmas. This discussion about plasma quenching efficiency of PMMA and PE will be made in later section again.

\section{Discussion}

\subsection{Comparison with experimental results}

6.1.1. Polymer vapour concentration distribution To verify the numerical calculation results, we compare them with experimental ones regarding the spatial distribution of polymer vapour and averaged particle velocity of polymer solid powder injected. For this purpose, we measure the radiation intensity distribution from $\mathrm{C}_{2}$-Swan molecular spectra at wavelengths around $468.2 \mathrm{~nm}$ from the polymer-ablated vapour using a highspeed video camera with a band-pass filter. The band-pass filter used for this study has a centre wavelength of $472.04 \mathrm{~nm}$ and a full width at half maximum (FWHM) of 9.44 
$\mathrm{nm}$. The frame rate was set to $1000 \mathrm{fps}$; and the exposure time for each frame was set to $300 \mu \mathrm{s}$. Experimental conditions were identical to those for the calculation condition described in section 4.7. The powder feed rate was set to $1 \mathrm{~g} \mathrm{~min}^{-1}$ using a powder feeder.

Figure 13 shows typical still images from a high-speed video with the band-pass filter. Panels (a), (b), (c) and (d) in this figure respectively present images of an $\mathrm{Ar}$ plasma without any polymer solid powder injection, an Ar plasma with PTFE solid powder injection, that with PMMA solid powder injection, that with PE solid powder injection, and that with POM solid powder injection. For Ar plasma without any polymer injection, weak intensity from the Ar plasma itself is visible in panel (a). This weak light is attributed mainly to the continuous recombination radiation in the $\mathrm{Ar}$ plasma. In cases of polymer-soiled powder injections, bright intensity is visible in the surrounding powders. This bright light arises from $\mathrm{C}_{2}$-Swan spectra in polymer-ablated vapour. In addition, a high-intensity region apparently covers the whole plasma torch inner space like 'a veil' in PTFE, PMMA, and PE powder injection cases. The strongest intensity is apparent in the $\mathrm{PE}$ injection case. On the other hand, a small bright intense region is apparent because of the POM-powder-injected Ar plasma.

This radiation intensity of $\mathrm{C}_{2}$ spectra is directly related to the $\mathrm{C}_{2}$ density excited at upper levels of the $\mathrm{C}_{2}$-Swan system. Such a $\mathrm{C}_{2}$ density distribution in an Ar plasma with polymer solid powder injection can be predicted from numerical simulations. Combining (i) $\mathrm{C}_{2}$ density in the calculated equilibrium composition of Ar-polymer vapour plasmas like figure 4 and (ii) distributions of temperature and polymer vapour concentration in thermal plasmas such as figures 9 and 11 enables the estimation of $\mathrm{C}_{2}$ mass fraction distributions in the plasma torch. Figure 14 shows the $\mathrm{C}_{2}$ molecule number densities in 100\% polymer-ablated vapour as a function of temperature at a pressure of 101325 $\mathrm{Pa}$. These data can be picked out from the calculated equilibrium composition such as those depicted in figure 4. The PMMA and PE vapours have similar $\mathrm{C}_{2}$ number density, whereas the PTFE vapour has a higher $\mathrm{C}_{2}$ number density than the PMMA and PE vapours. On the other hand, the POM vapour clearly has a much lower $\mathrm{C}_{2}$ number density than the others at temperatures higher than $3000 \mathrm{~K}$. This $\mathrm{C}_{2}$ number density depends on the composition of $\mathrm{C}, \mathrm{H}$, and $\mathrm{O}$ or $\mathrm{F}$ atoms in polymer-ablated vapours in an equilibrium condition.

Figure 15 shows the estimated $\mathrm{C}_{2}$ mass fraction distribution in Ar plasmas in the plasma torch with PTFE, POM, PMMA, and PE solid powder injections in logarithm scale. The PTFE, PMMA, and PE injection cases show a high $\mathrm{C}_{2}$ mass fraction region just under the water-cooled pipe and also surrounding the plasma near the torch head and torch wall. However, the $\mathrm{C}_{2}$ mass fraction is low in the case of POM injection. The calculated $\mathrm{C}_{2}$ mass fraction distribution in figure 15 is comparable to the experimentally obtained radiation intensity from $\mathrm{C}_{2}$ molecules in figure 13. Good agreement between them is apparent, although the radiation intensity does not directly indicate the $\mathrm{C}_{2}$ molecule density or the mass fraction because it depends not only on the whole $\mathrm{C}_{2}$ number density but also on the $\mathrm{C}_{2}$ excited at a energy upper level depending on 
the electronic excitation temperature, the vibrational temperature, and the rotational temperature.

6.1.2. Particle velocity From high-speed video camera images, we can distinguish some injected particles, as portrayed in figure 13. Using these images, the order of the travelling velocity of injected particles can be estimated. The high-speed video camera image is only two-dimensional. For that reason, the estimated velocity might be underestimated. In addition, we assumed a complete sphere shape for a polymer particle, uniform heat tranfer from plasmas to a particle, no charging effect, etc in the present model. These may bring some deviations between experimental and calulated results. In spite of this, we can compare particle velocity in terms of its order.

Figure 16(a) shows the velocity distributions of injected PTFE particles, as estimated from the experiment. The velocity distributions were estimated from 50 particle movements between the first and second coils of the plasma torch. The PTFE particles have a velocity of $0.1-2.0 \mathrm{~m} \mathrm{~s}^{-1}$. The averaged velocity is evaluated as 1.2 $\mathrm{m} \mathrm{s}^{-1}$. For other polymer particles, the particle velocity was experimentally measured and found to be of a similar order to 1-2 $\mathrm{m} \mathrm{s}^{-1}$. On the other hand, the particle velocity distributions are calculable from the numerical simulation for the same region between the first and second coils of the plasma torch. The calculated velocity distribution of injected PTFE particles is shown in figure 16(b). As portrayed in that figure, the order of particle velocities around $1-2 \mathrm{~m} \mathrm{~s}^{-1}$ is similar between the experimental and calculated results. This comparison shows that we can justify a certain validity of the present modelling.

\subsection{Dominant process for temperature decay of thermal plasma}

The decay of the thermal plasma temperature is considered mainly to arise from two effects: That of properties of polymer-ablated vapour, and that of properties of the polymer in solid and liquid phases.

To elucidate effects of thermodynamic and transport properties of polymer-ablated vapour on the temperature decay of the Ar thermal plasma, we calculated the temperature of Ar thermal plasma with polymer solid powder injection under the same conditions in section 4.7, except for the fact that we used the thermodynamic and transport properties of Ar gas as a polymer-ablated vapour instead of those of polymerablated vapour. For solid and liquid phases, the proper thermodynamic properties were used. Figure 17 depicts the temperature distribution of Ar thermal plasma for the above calculation. Panels (a), (b), (c), and (d) respectively correspond to results for PTFE, PMMA, PE, and POM powder injection. As shown, there is little difference in the temperature distribution of Ar thermal plasma for any case. The small scale of the differences means that thermodynamic and transport properties of polymer-ablated vapours are related mainly with the marked temperature decay of Ar thermal plasmas in figure 9 . In addition, it can be considered that thermodynamic properties of polymers 
in solid and liquid phases only negligibly affect the temperature of Ar thermal plasmas.

We calculated the temperature distribution in case of $0.1 \%$ polymer-ablated vapour premixing only for fundamental study to clarify the effect of thermodynamic and transport properties of polymer-ablated vapours. Figure 18 represents the temperature of $99.9 \%$ Ar- $0.1 \%$ polymer-ablated vapour thermal plasmas. Panels (a), (b), (c), and (d) respectively show data for PTFE, PMMA, PE, and POM vapour inclusion. As shown there, PMMA-ablated vapour inclusion causes the lowest temperature of $\mathrm{Ar}$ thermal plasma, which indicates that PMMA-ablated vapour itself has a higher plasmaquenching efficiency than the others. The plasma-quenching efficiency is related to the specific heat $C_{\mathrm{p}}$ at lower temperatures [17]. As portrayed in figure 5, PMMA has a higher $C_{\mathrm{p}}$ at temperatures below $3000 \mathrm{~K}$, which produces a large convection loss $\rho C_{\mathrm{p}} \boldsymbol{u} \cdot \nabla T$ [17]. Consequently, the PMMA solid powder injection degrades the thermal plasma temperature, as portrayed in figure 9. On the other hand, PE has a lower melting and evaporation temperature and lower latent heats, which causes a larger amount of ablated vapour. This reason explains why PE solid powder injection causes a large decay of the temperature of Ar plasmas.

\section{Conclusions}

A numerical simulation was made for temperature decay of thermal plasmas by injection of polymer solid powders. This model incorporated thermal interactions between the thermal plasma and the particle. Calculation results were in good agreement with the experimental results from the viewpoint of distribution of polymer vapor concentration and averaged particle velocity, and showed that injection of PMMA or PE increases temperature decay than PTFE and POM. The PMMA vapor itself has a higher specific heat at temperatures below $5000 \mathrm{~K}$, which increases convection loss. The PE has lower melting and boiling temperatures, which brings high density of polymer vapor. Combining results of experiments and calculations of induction thermal plasmas with polymer powders provides some insights into the plasma quenching efficiency of polymer ablated vapor.

\section{References}

[1] Ibrahim E Z 1980 The ablation dominated polymethylmethacrylate arc J. Phys. D: Appl. Phys. $132045-66$

[2] Andre P 1996 Composition and thermodynamic properties of ablated vapours of PMMA, PA6-6, PETP, POM and PE J. Phys. D: Appl. Phys. 29 1963-72

[3] Andre P 1997 The influence of graphite on the composition and thermodynamic properties of plasma formed in ablated vapour of PMMA, PA6-6, PETP, POM and PE used in circuit-breakers J. Phys. D: Appl. Phys. 30 475-93

[4] Chervy B, Riad H and Gleizes A 1996 Calculation of the interruption capability of $\mathrm{SF}_{6}-\mathrm{CF}_{4}$ and $\mathrm{SF}_{6}-\mathrm{C}_{2} \mathrm{~F}_{6}$ mixture - Part I: Plasma properties IEEE Trans. on Plasma Sci. 24 198-209

[5] Chervy B, Gonzalez J J and Gleizes A 1996 Calculation of the interruption capability of $\mathrm{SF}_{6}-\mathrm{CF}_{4}$ and $\mathrm{SF}_{6}-\mathrm{C}_{2} \mathrm{~F}_{6}$ mixtures. Part-II. Arc decay modeling IEEE Trans. on Plasma Sci. 24 210-17 
[6] Chevrier P, Barrault M, Fievet C, Maftoul J and Fremillon J M 1997 Industrial applications of high-, medium- and low-voltage arc modelling J. Phys. D: Appl. Phys. 30 1346-55

[7] Yan J D, Fang M T C and Hall W 1999 The development of PC based CAD tools for auto-expansion circuit breaker design IEEE Trans. Power Delivery 14 176-81

[8] Nielsen T, Kaddani A and Zahrai S 2001 Modelling evaporating metal droplets in ablation controlled electric arcs J. Phys. D: Appl. Phys. 34 2022-31

[9] Telfer D J, Humphries J, Spencer J W and Jones G R 2002 Influence of PTFE on arc quenching in an experimental self-pressurized circuit breaker XIV-th Int. Conf. Gas Discharges and their Applications 1 pp.91-4 (Liverpool, UK)

[10] Zhang J L, Yan J D and Fang M T C 2002 Prediction of arc behaviour during the current zero period in an auto-expansion circuit breaker XIV-th Int. Conf. Gas Discharges and their Applications 1 pp.131-4 (Liverpool, UK)

[11] Luders C, Suwanasri T and Dommerque R 2006 Investigation of an $\mathrm{SF}_{6}$-selfblast circuit breaker J. Phys. D: Appl. Phys. 39 666-72

[12] Seeger M 2006 An integral arc model for ablation controlled arcs based on CFD simulations $J$. Phys. D: Appl. Phys. 39 2180-91

[13] Seeger M, Tepper J, Christen T and Abrahamson J 2006 Experimental study on PTFE ablation in high-voltage circuit-breakers J. Phys. D: Appl. Phys. 39 5016-24

[14] Kozakov R, Kettlitz M, Weltmann K-D, Steffens A and Franck C M 2007 Temperature profiles of an ablation controlled arc in PTFE: I. Spectroscopic measurements J. Phys. D: Appl. Phys. 40 2499-506

[15] Tsukima M, Mitsuhashi T, Takahashi M, Fushimi M, Hosogai S and Yamagata S 2002 Lowvoltage Circuit Breaker using Auto-puffer Interruption Technique Trans. IEEJ 122-PE 969-75 (in Japanese)

[16] Uchii T, Hoshina Y, Miyazaki K, Mori T, Kawano H, Nakamoto T and Hirano Y 2004 Development of 72-kV Class Environmentally Benign $\mathrm{CO}_{2}$ Gas Circuit Breaker Model Trans. IEEJ 124-PE 476-84 (in Japanese)

[17] Tanaka Y and Sakuta T 2002 Investigation of plasma-quenching efficiency of various gases using induction thermal plasma technique: effect of various gas injection on Ar thermal ICP J. Phys. D: Appl. Phys. 35 2149-58

[18] Wang C, Tanaka Y and Sakuta T 2004 Modeling of Ar Induction Thermal Plasma with an Injection of PTFE Powder Trans. IEEJ 124-PE 440-46

[19] Tanaka Y, Numada T, Kaneko S and Okabe S 2005 Thermodynamic and transport properties of polymer ablated vapors and influence of their inclusions on Ar induction thermal plasma temperature JSME International Journal Ser. B 48 417-24

[20] Tanaka Y, Numada T, Uesugi Y, Kaneko S and Okabe S 2005 Influence of polymer vapor concentration on temperature of Ar induction thermal plasmas during polymer solid powder injections Trans. IEEJ 125-PE 1077-83

[21] Takeuchi Y, Tanaka Y, Uesugi Y, Kaneko S and Okabe S 2007 Numerical simulation of thermal interaction between polymer and Ar induction thermal plasma Trans. IEEJ 127-PE 739-46

[22] Crowe C T , Sharma M P and Stock D E 1977 The particle-source-in cell (PSI-Cell) model for gas-droplet flows J. Fluids Eng. 99 325-32

[23] Proulx P, Mostaghimi J and Boulos M I 1985 Plasma-particle interaction effects in induction plasma modeling under dense loading conditions Int. J. Heat Mass Transfer 28 1327-36

[24] Proulx P, Mostaghimi J and Boulos M I 1987 Heating of powder in an r.f. inductively coupled plasma under dense loading conditions Plasma Chem. Plasma Process. 7 29-52

[25] Boulos M I, Fauchais P and Pfender E 1994 Thermal Plasma Fundamentals and Applications vol. 1 (Plenum Press) pp 366-9

[26] Tanaka Y and Sakuta T 2002 Chemically non-equilibrium modeling of $\mathrm{N}_{2}$ thermal ICP at atmospheric pressure J. Phys. D: Appl. Phys. $35468-76$

[27] Tanaka Y 2004 Two-temperature chemically non-equilibrium modelling of high-power Ar- $\mathrm{N}_{2}$ 
inductively coupled plasma at atmospheric pressure J. Phys. D: Appl. Phys. 37 1190-1205 (Selected as a leading paper in 2004 in J. Phys. D: Appl. Phys. )

[28] Tanaka Y 2006 Time-dependent two-temperature chemically non-equilibrium modelling of highpower Ar- $\mathrm{N}_{2}$ pulse-modulated inductively coupled plasmas at atmospheric pressure J. Phys. D: Appl. Phys. 39 307-309

[29] Yos J M 1963 Transport properties of nitrogen, hydrogen, oxygen and air to $30000 \mathrm{~K}$, AVCO Technical Memorandum RAD-TM-63-7

[30] Chapman S and Cowling T G 1970 The Mathematical Theory of Non-Uniform Gases Third Edition (Cambridge University Press)

[31] Devoto R S 1967 Transport coefficients of partially ionized argon Phys. Fluid 10 354-64

[32] Tanaka Y, Paul K C and Sakuta T 2000 Thermodynamic and transport properties of $\mathrm{N}_{2} / \mathrm{O}_{2}$ mixtures at different admixture ratios T. IEE of Japan 120-PE 24-30

[33] Polymer database PolyInfo, National Institute for Material Science (NIMS) http://polymer.nims.go.jp/

[34] Patankar S V 1980 Numerical Heat Transfer and Fluid Flow (Hemisphere Publishing) 


\section{Tables and table captions}

Table 1. Size distribution and fraction of powder.

\begin{tabular}{ll}
\hline Diameter $[\mu \mathrm{m}]$ & Fraction \\
\hline 270 & 0.03 \\
280 & 0.07 \\
290 & 0.1 \\
300 & 0.6 \\
310 & 0.1 \\
320 & 0.07 \\
330 & 0.03 \\
\hline
\end{tabular}


Table 2. Thermodynamic properties of polymer powders.

\begin{tabular}{llllll}
\hline Polymers & PTFE & PMMA $^{*}$ & PE & POM & (Ref.) \\
\hline Average diameter $[\mu \mathrm{m}]$ & 300 & 300 & 300 & 300 & Measured \\
Mass density $\left[\mathrm{kg} \mathrm{m}^{-3}\right]$ & 2160 & 1163 & 932 & 1410 & {$[33]$} \\
Melting temperature $[\mathrm{K}]$ & 618 & - & 406 & 435 & Measured \\
Boiling/thermal decomposition temperature $[\mathrm{K}]$ & 809 & 618 & 734 & 605 & Measured \\
Latent heat for melting $\left[\mathrm{kJ} \mathrm{kg}^{-1}\right]$ & 50.4 & - & 191 & 123 & Measured \\
Latent heat for evaporation $\left[\mathrm{kJ} \mathrm{kg}^{-1}\right]$ & 936.7 & 251.6 & 75.5 & 1022 & Measured \\
Specific heat of solid $\left[\mathrm{J} \mathrm{kg}^{-1} \mathrm{~K}^{-1}\right]$ & 1035 & 1779 & 2408 & 1983 & Measured \\
Specific heat of liquid $\left[\mathrm{J} \mathrm{kg}^{-1} \mathrm{~K}^{-1}\right]$ & 1419 & 1919 & 2763 & 2099 & Measured \\
Thermal conductivity $\left[\mathrm{W} \mathrm{m} \mathrm{K}^{-1} \mathrm{~K}^{-1}\right]$ & 0.25 & 0.2 & 0.34 & 0.3 & {$[33]$} \\
Emissivity of particle source $[-]$ & 0.3 & 0.3 & 0.3 & 0.3 & {$[33]$} \\
\hline
\end{tabular}

*Amorphous 
Table 3. Total amount of mass and energy loss for polymer powder ablation.

\begin{tabular}{lllll}
\hline Polymers & PTFE & PMMA & PE & POM \\
\hline Ablation mass [mg s & \\
Energy loss for ablation $[\mathrm{W}]$ & 2.65217 & 2.65258 & 2.65251 & 2.65259 \\
\hline
\end{tabular}




\section{Figure captions}

Figure 1. Photographic image of PTFE powders.

Figure 2. Plasma torch configuration and calculation space.

Figure 3. Concept and definition of parameters in the temperature calculation inside the polymer particle.

Figure 4. Equilibrium composition of 50\%Ar-50\% PTFE ablated vapour at atmospheric pressure.

Figure 5. Specific heat of $90 \%$ Ar- $10 \%$ polymer vapour at atmospheric pressure.

Figure 6. Time evolution in radial temperature distributions inside a test PTFE particle injected into Ar thermal plasmas: (a) $t_{\mathrm{p}}=5 \mathrm{~ms}, z_{\mathrm{p}}=9.20 \mathrm{~mm}$; (b) $t_{\mathrm{p}}=25 \mathrm{~ms}$, $z_{\mathrm{p}}=43.76 \mathrm{~mm}$; and (c) $t_{\mathrm{p}}=30 \mathrm{~ms}, z_{\mathrm{p}}=49.45 \mathrm{~mm}$, where $t_{\mathrm{p}}$ is the time after particle injection, and $z_{\mathrm{p}}$ is the axial position of a particle in the plasma torch.

Figure 7. Temperature variation in each shell inside a test PTFE particle injected into Ar thermal plasmas.

Figure 8. Temperature distribution of Ar thermal plasmas at atmospheric pressure with input power of $30 \mathrm{~kW}$. (a) with Ar sheath gas; (b) with Ar sheath and centre carrier gases; (c) with Ar sheath and centre carrier gases, and PTFE powder injection

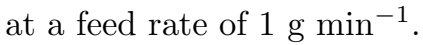


Figure 9. Temperature distributions of Ar thermal plasmas at atmospheric pressure with (a) PTFE, (b) PMMA, (c) PE, and (d) POM solid powder injections. The powder feed rate is $1 \mathrm{~g} \mathrm{~min}^{-1}$.

Figure 10. Radial temperature distributions of Ar thermal plasmas with polymer powder injections at the axial position of $95 \mathrm{~mm}$. The powder feed rate is $1 \mathrm{~g} \mathrm{~min}^{-1}$.

Figure 11. Mass fraction distribution of polymer-ablated vapours in Ar thermal plasmas at atmospheric pressure. The powder feed rate is $1 \mathrm{~g} \mathrm{~min}^{-1}$. (a) PTFE (b) PMMA (c) PE (d) POM injection cases

Figure 12. Streamline for Ar thermal plasma with injections of (a) PTFE, (b) PMMA, (c) PE, and (d) POM. The powder feed rate is $1 \mathrm{~g} \mathrm{~min}^{-1}$.

Figure 13. Video captured image with a band pass filter for Ar thermal plasmas with polymer powder injection. The centre wavelength of the band pass filter is $472.04 \mathrm{~nm}$; its FWHM is $9.44 \mathrm{~nm}$. The measured radiation intensity from Ar thermal plasmas with polymer powder injection results mainly from the $\mathrm{C}_{2}$-Swan molecular spectra. The powder feed rate is $1 \mathrm{~g} \mathrm{~min}^{-1}$. (a) no polymer (b) PTFE (c) PMMA (d) PE (e) POM injection cases

Figure 14. The $\mathrm{C}_{2}$ number density in $100 \%$ polymer-ablated vapours under equilibrium conditions at atmospheric pressure.

Figure 15. The calculated mass fraction distribution of $\mathrm{C}_{2}$ molecule in Ar thermal plasmas with polymer powder injection. (a) PTFE (b) PMMA (c) PE (d) POM injection cases

Figure 16. The experimentally measured and numerically calculated velocity distributions of injected PTFE particles into Ar thermal plasmas. The velocity distribution was estimated between the first and second coils of the plasma torch. (a) Experimentally measured (b) Numerically calculated

Figure 17. Temperature distribution of Ar thermal plasma with polymer solid powder injection. Thermodynamic and transport properties of Ar are used imaginarily for those of polymer-ablated vapours instead of their real polymer vapour properties. (a) PTFE; (b) PMMA; (c) PE; (d) POM.

Figure 18. Temperature distribution of Ar thermal plasma with $0.1 \%$ premixed polymer-ablated vapour. No centre gas is fed. (a) PTFE (b) PMMA (c) PE (d) POM 


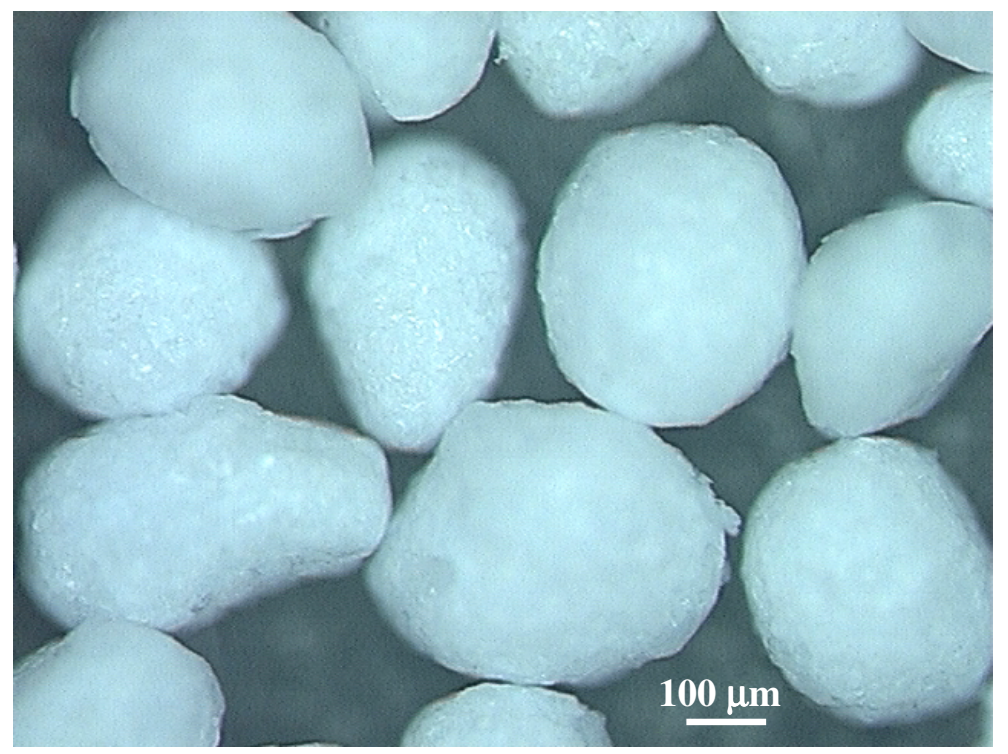

Figure 1. Photographic image of PTFE powders. 


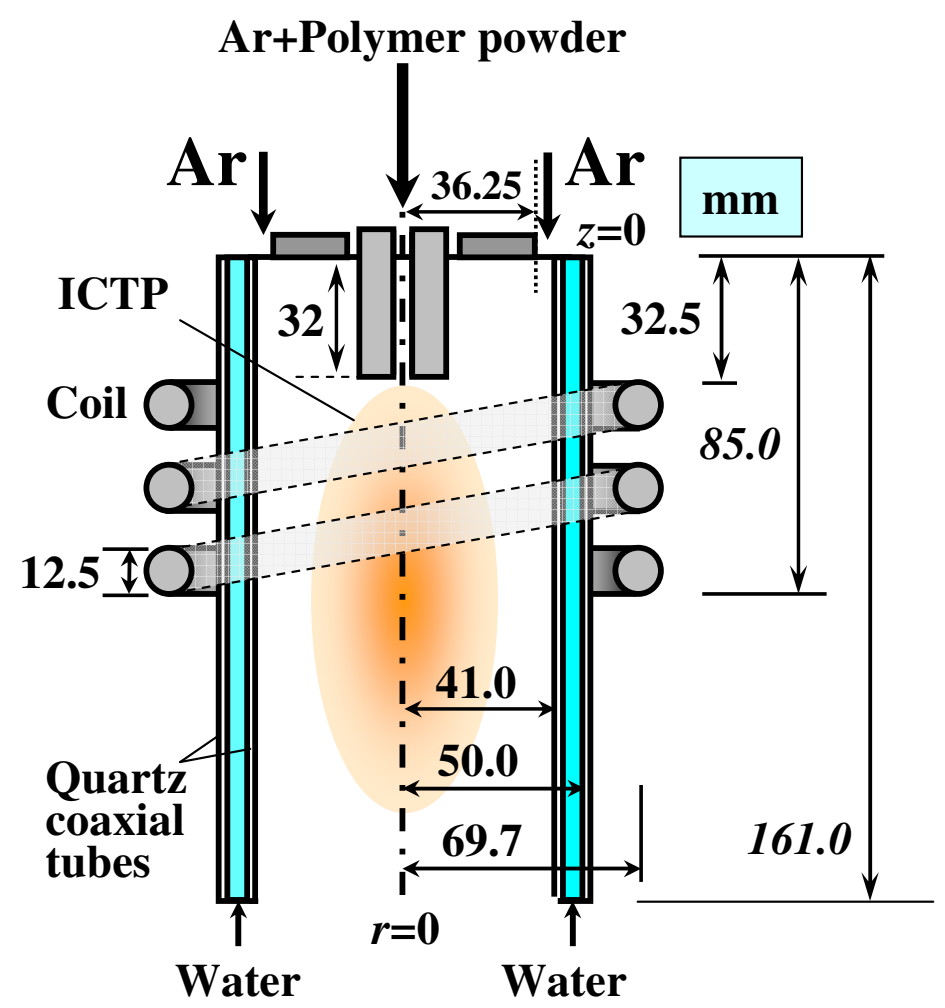

Figure 2. Plasma torch configuration and calculation space. 


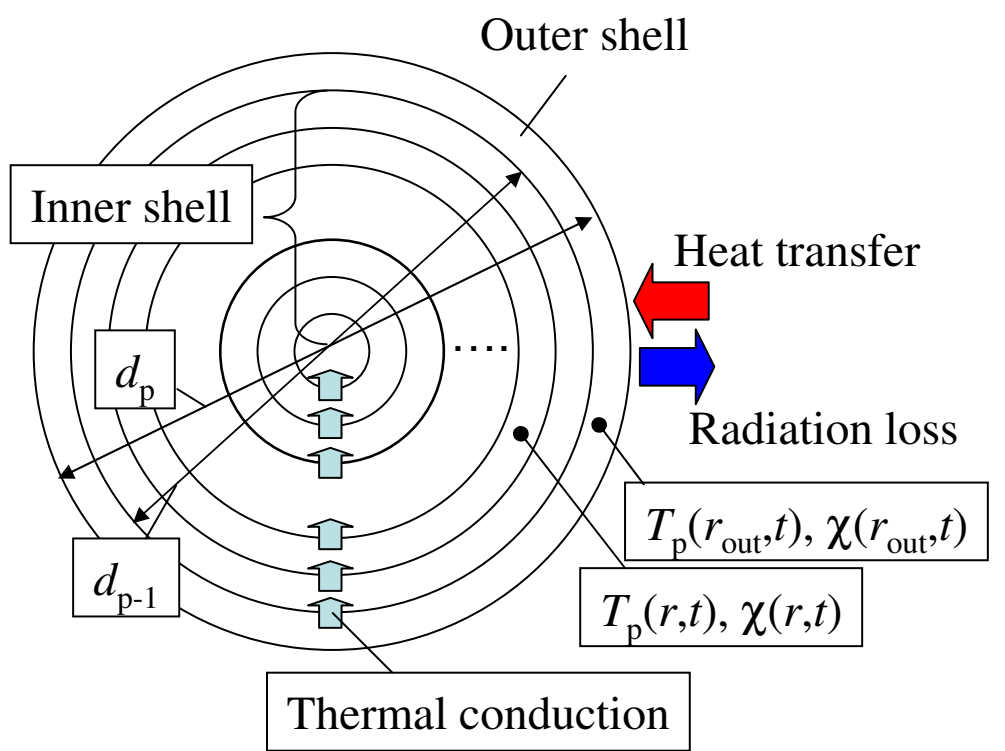

Figure 3. Concept and definition of parameters in the temperature calculation inside the polymer particle. 


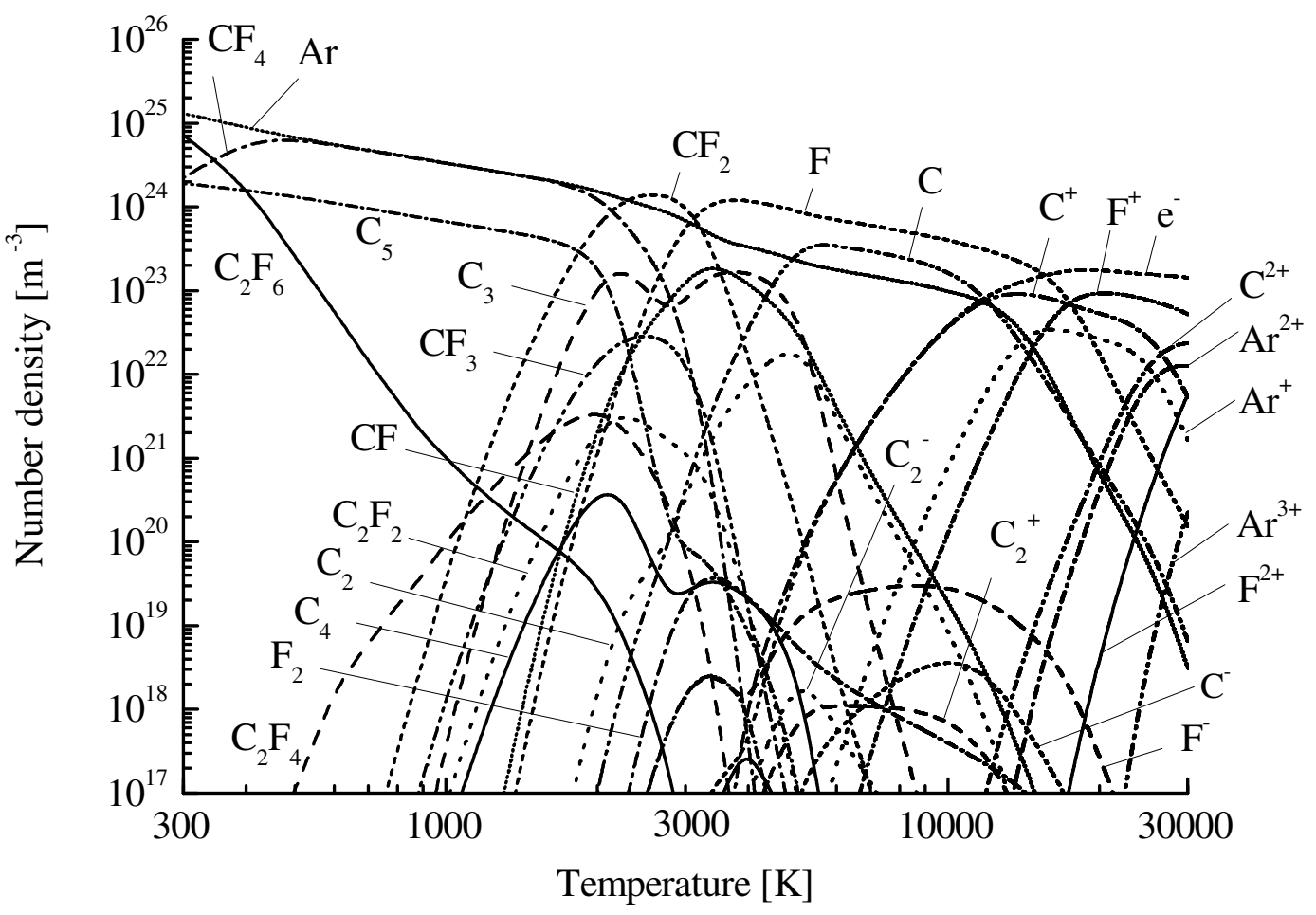

Figure 4. Equilibrium composition of $50 \%$ Ar- $50 \%$ PTFE ablated vapour at atmospheric pressure. 


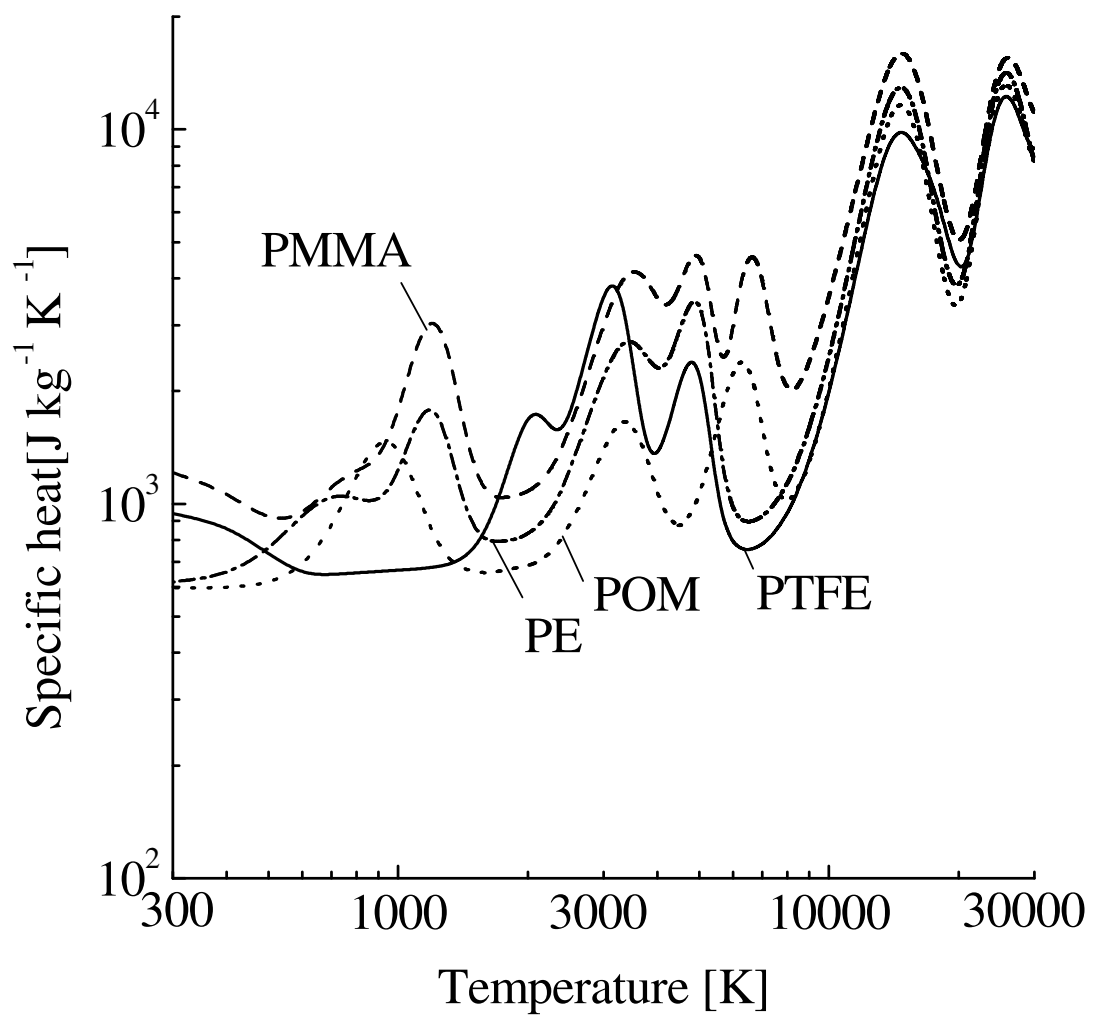

Figure 5. Specific heat of $90 \%$ Ar- $10 \%$ polymer vapour at atmospheric pressure. 


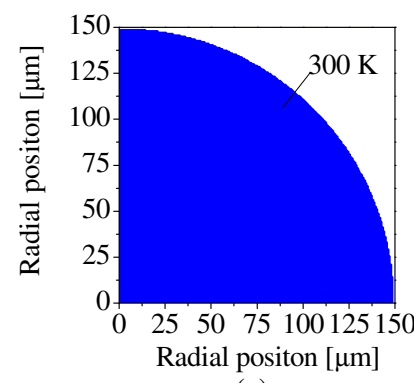

(a)

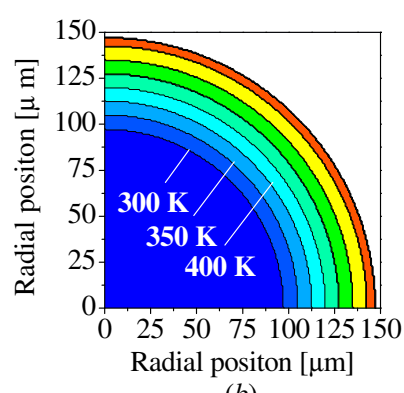

(b)

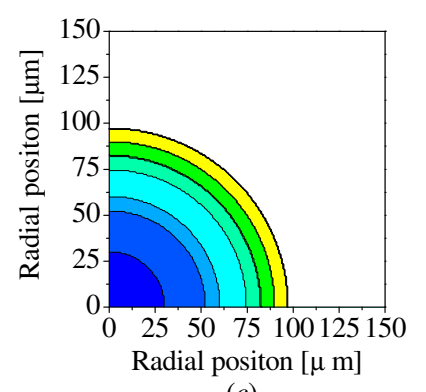

(c)

Figure 6. Time evolution in radial temperature distributions inside a test PTFE particle injected into Ar thermal plasmas: (a) $t_{\mathrm{p}}=5 \mathrm{~ms}, z_{\mathrm{p}}=9.20 \mathrm{~mm}$; (b) $t_{\mathrm{p}}=25 \mathrm{~ms}$, $z_{\mathrm{p}}=43.76 \mathrm{~mm}$; and (c) $t_{\mathrm{p}}=30 \mathrm{~ms}, z_{\mathrm{p}}=49.45 \mathrm{~mm}$, where $t_{\mathrm{p}}$ is the time after particle injection, and $z_{\mathrm{p}}$ is the axial position of a particle in the plasma torch. 


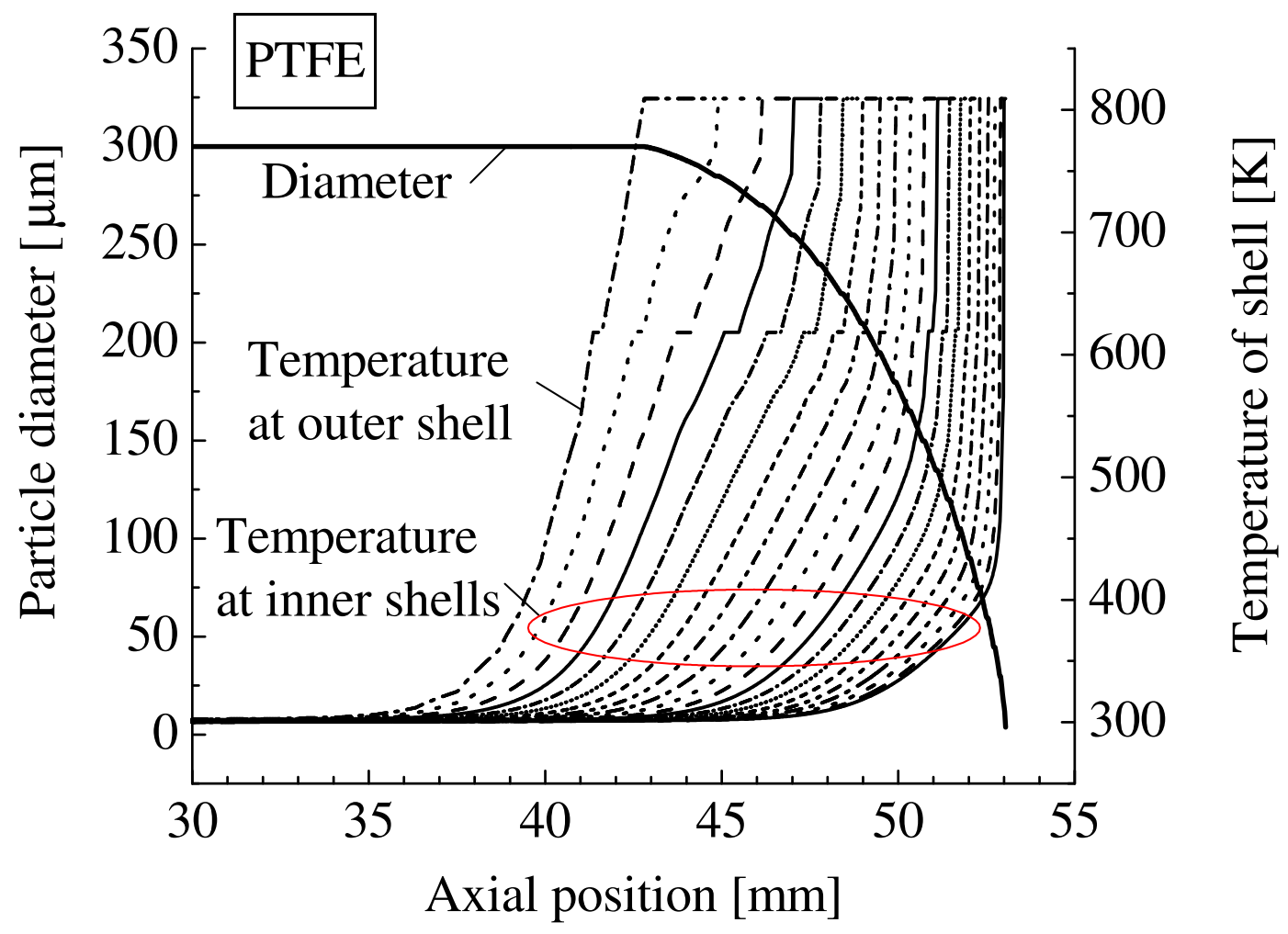

Figure 7. Temperature variation in each shell inside a test PTFE particle injected into Ar thermal plasmas. 


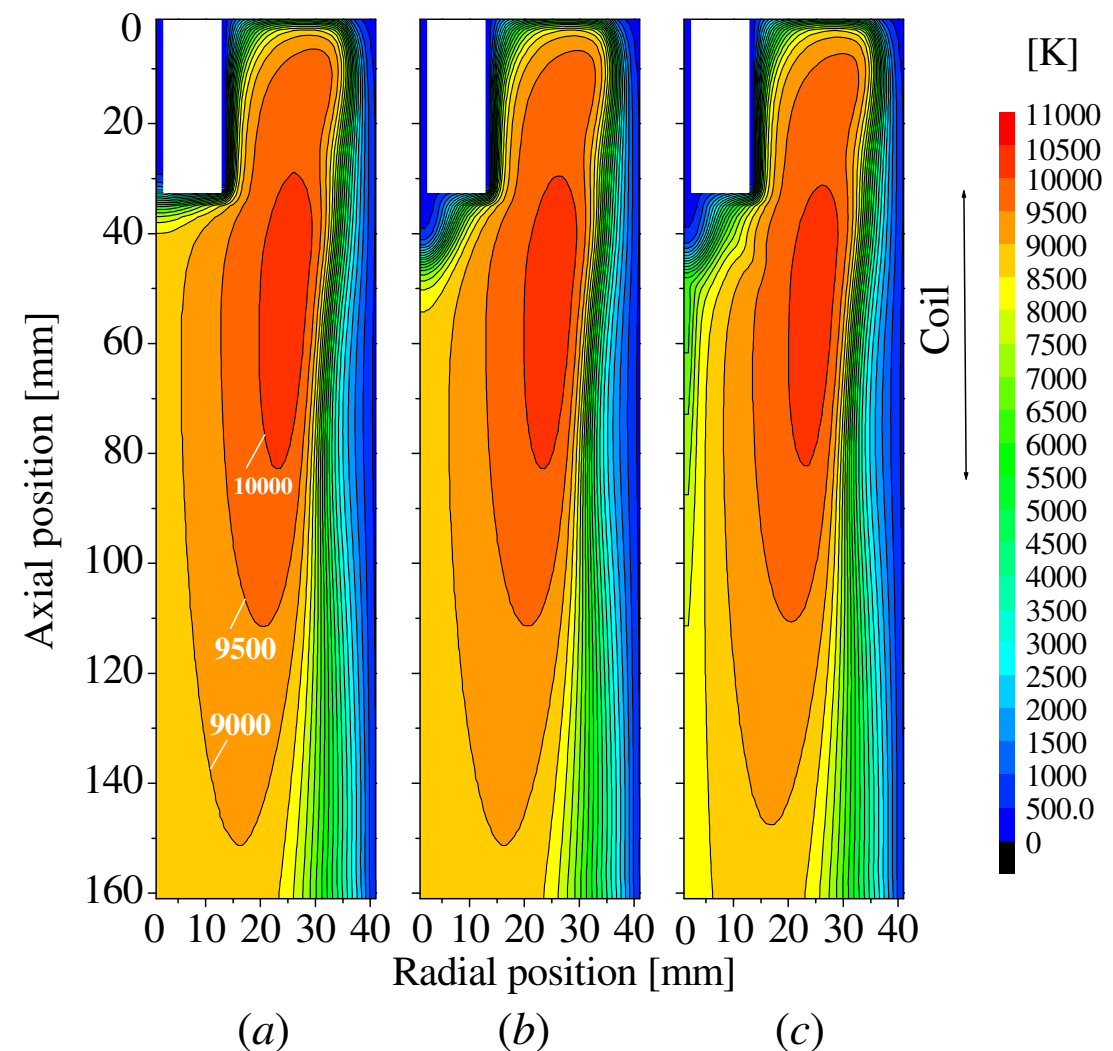

Figure 8. Temperature distribution of Ar thermal plasmas at atmospheric pressure with input power of $30 \mathrm{~kW}$. (a) with Ar sheath gas; (b) with Ar sheath and centre carrier gases; (c) with Ar sheath and centre carrier gases, and PTFE powder injection at a feed rate of $1 \mathrm{~g} \mathrm{~min}{ }^{-1}$. 


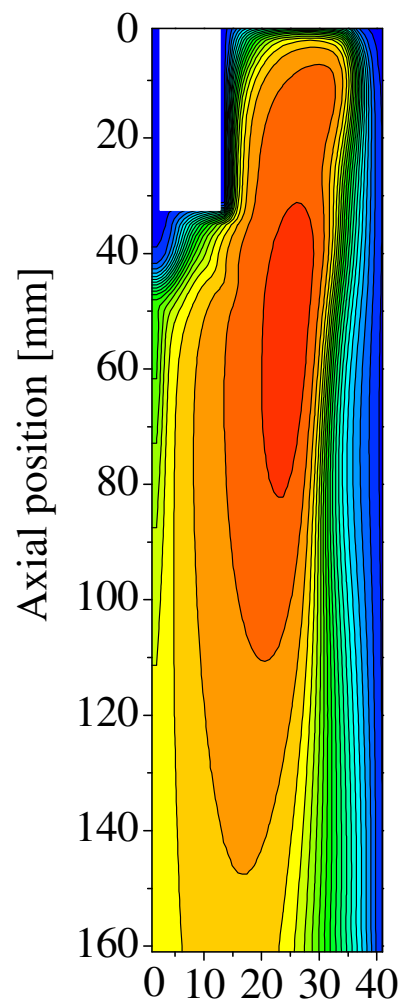

(a)
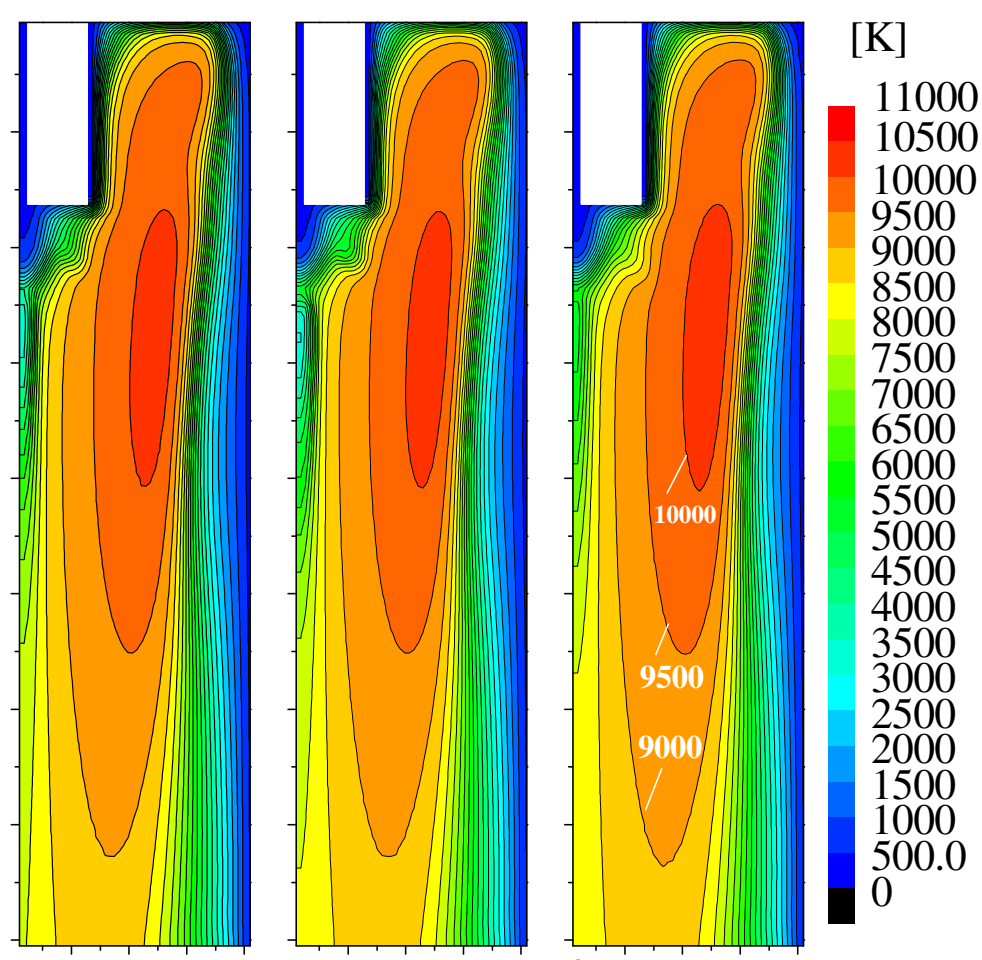

Radial position [mm]

(b)

(c)

(d)

Figure 9. Temperature distributions of Ar thermal plasmas at atmospheric pressure with (a) PTFE, (b) PMMA, (c) PE, and (d) POM solid powder injections. The powder feed rate is $1 \mathrm{~g} \mathrm{~min}^{-1}$. 


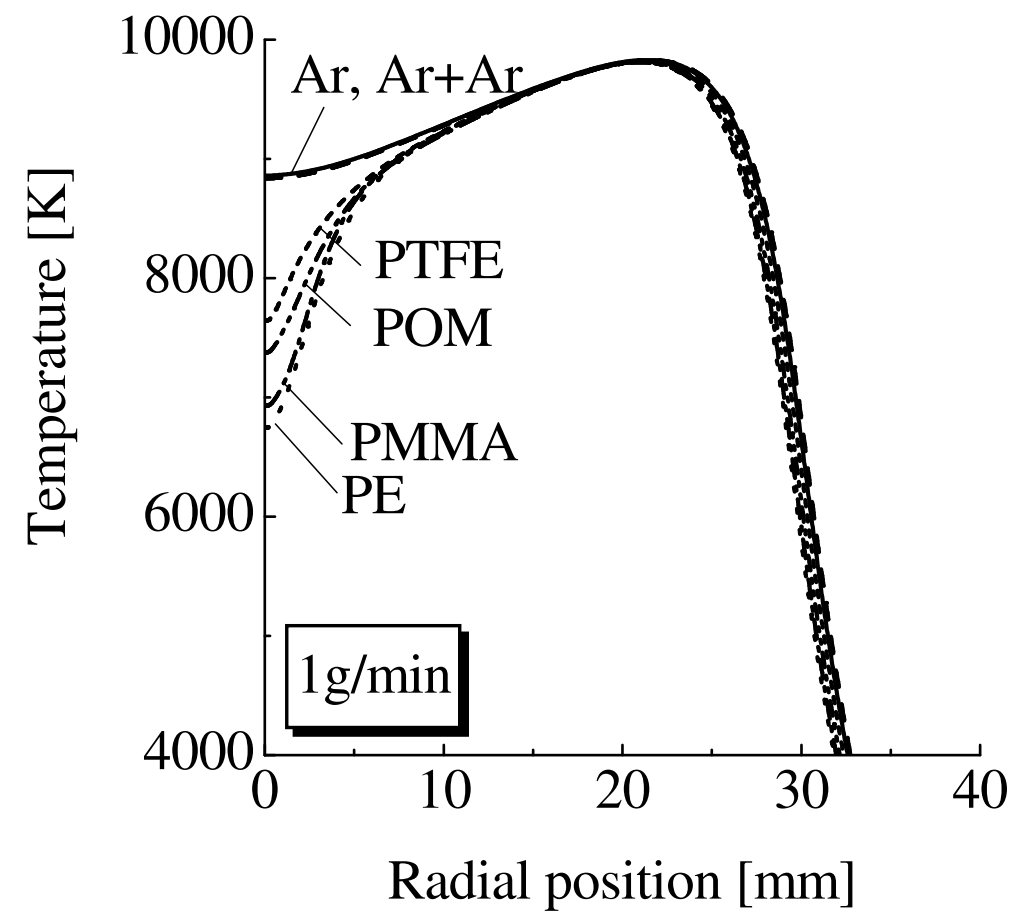

Figure 10. Radial temperature distributions of Ar thermal plasmas with polymer powder injections at the axial position of $95 \mathrm{~mm}$. The powder feed rate is $1 \mathrm{~g} \mathrm{~min}^{-1}$. 


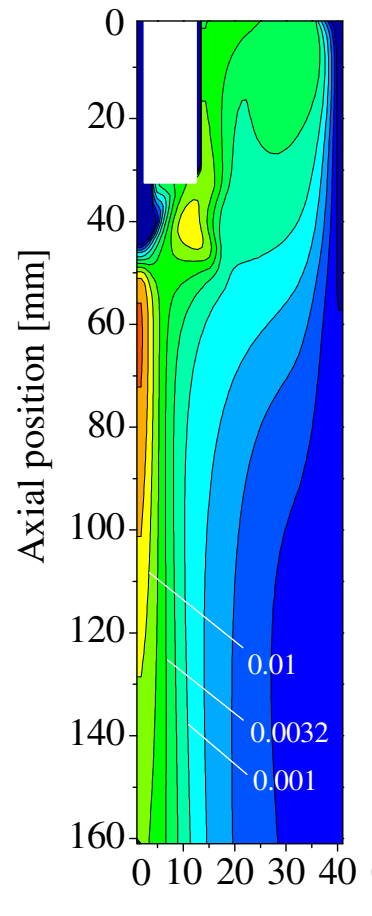

(a)
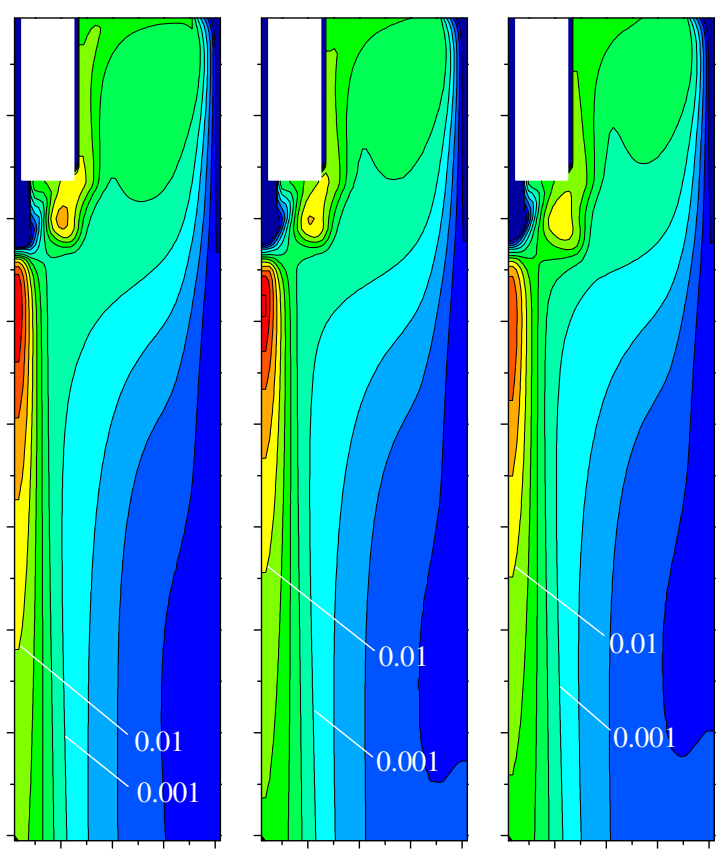

Radial position $[\mathrm{mm}]$

(c)

(d)

Figure 11. Mass fraction distribution of polymer-ablated vapours in Ar thermal plasmas at atmospheric pressure. The powder feed rate is $1 \mathrm{~g} \mathrm{~min}^{-1}$. (a) PTFE (b) PMMA (c) PE (d) POM injection cases. 


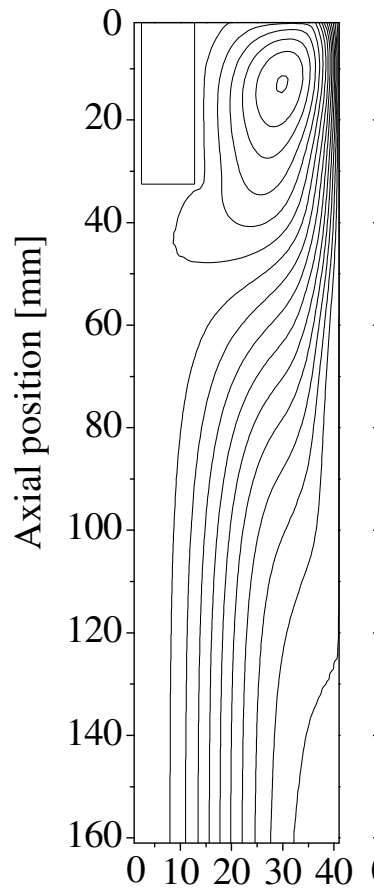

(a)
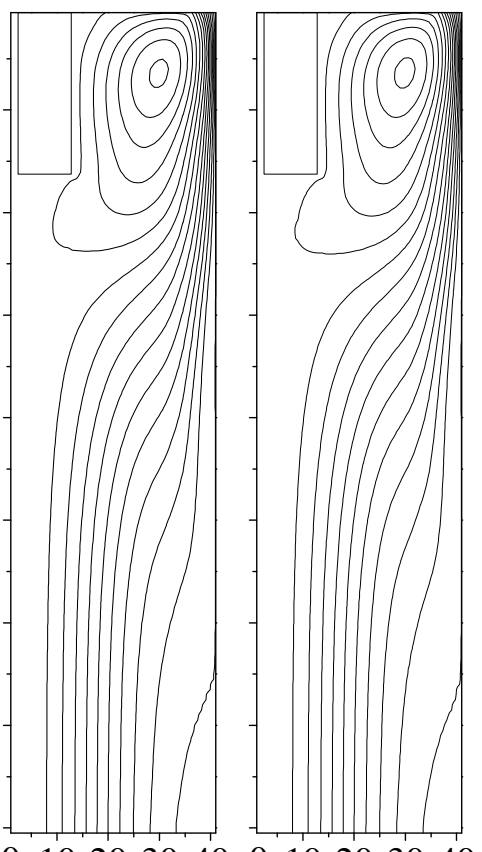

$\begin{array}{llllllllll}0 & 10203040 & 0 & 10203040\end{array}$

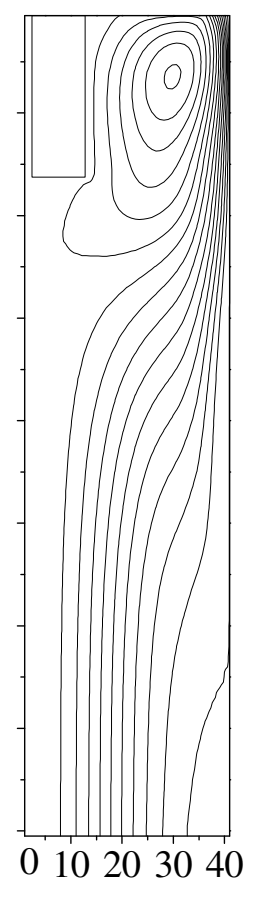

(d)

Figure 12. Streamline for Ar thermal plasma with injections of (a) PTFE, (b) PMMA, (c) PE, and (d) POM. The powder feed rate is $1 \mathrm{~g} \mathrm{~min}^{-1}$. 


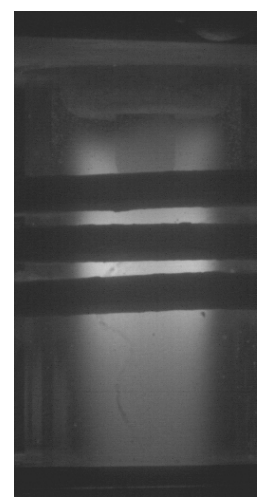

(a)

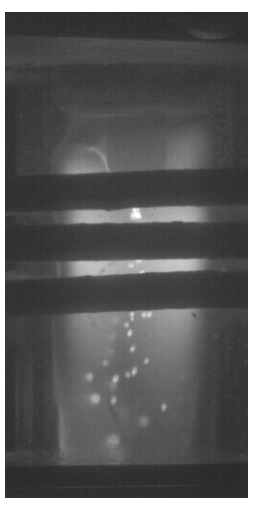

(b)

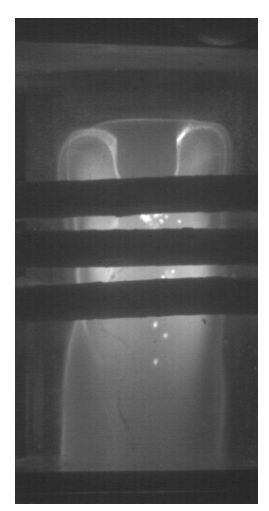

(c)

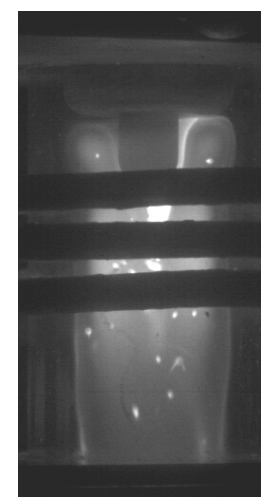

$(d)$

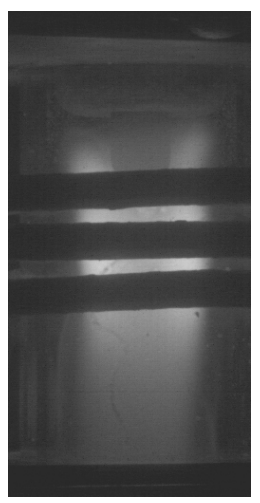

(e)

Figure 13. Video captured image with a band pass filter for Ar thermal plasmas with polymer powder injection. The centre wavelength of the band pass filter is $472.04 \mathrm{~nm}$; its FWHM is $9.44 \mathrm{~nm}$. The measured radiation intensity from Ar thermal plasmas with polymer powder injection results mainly from the $\mathrm{C}_{2}$-Swan molecular spectra. The powder feed rate is $1 \mathrm{~g} \mathrm{~min}^{-1}$. (a) no polymer (b) PTFE (c) PMMA (d) PE (e) POM injection cases 


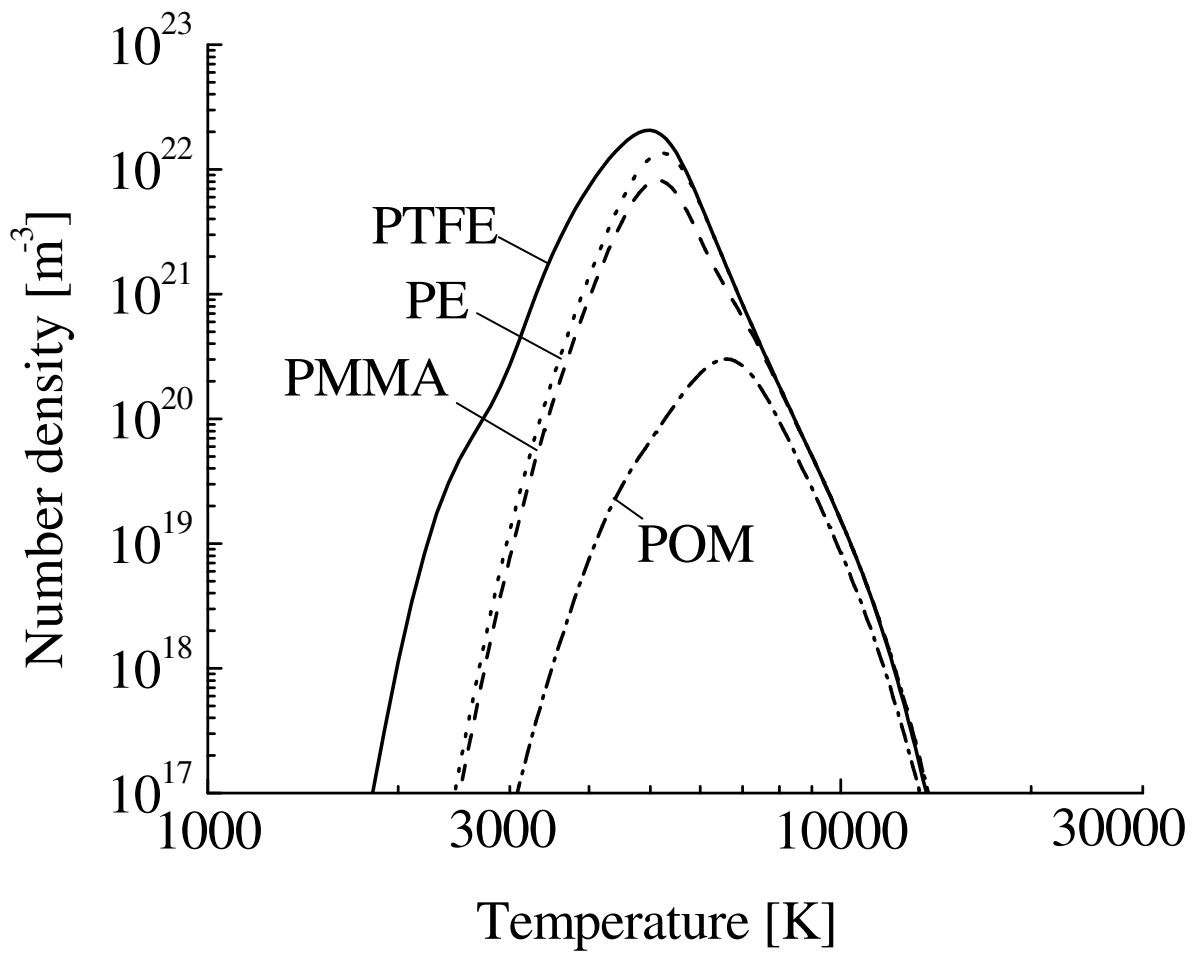

Figure 14. The $\mathrm{C}_{2}$ number density in $100 \%$ polymer-ablated vapours under equilibrium conditions at atmospheric pressure. 


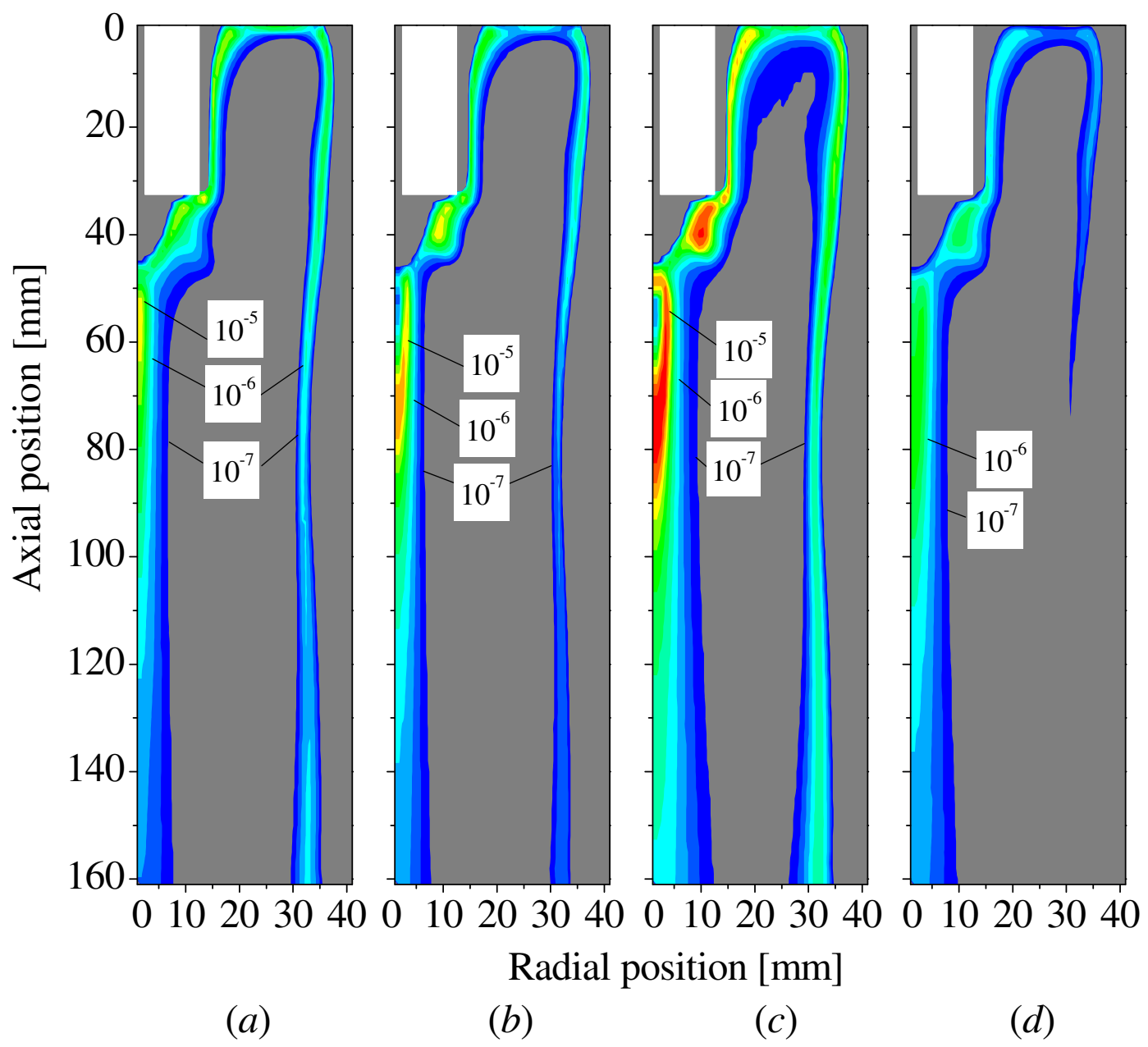

Figure 15. The calculated mass fraction distribution of $\mathrm{C}_{2}$ molecule in Ar thermal plasmas with polymer powder injection. (a) PTFE (b) PMMA (c) PE (d) POM injection cases 

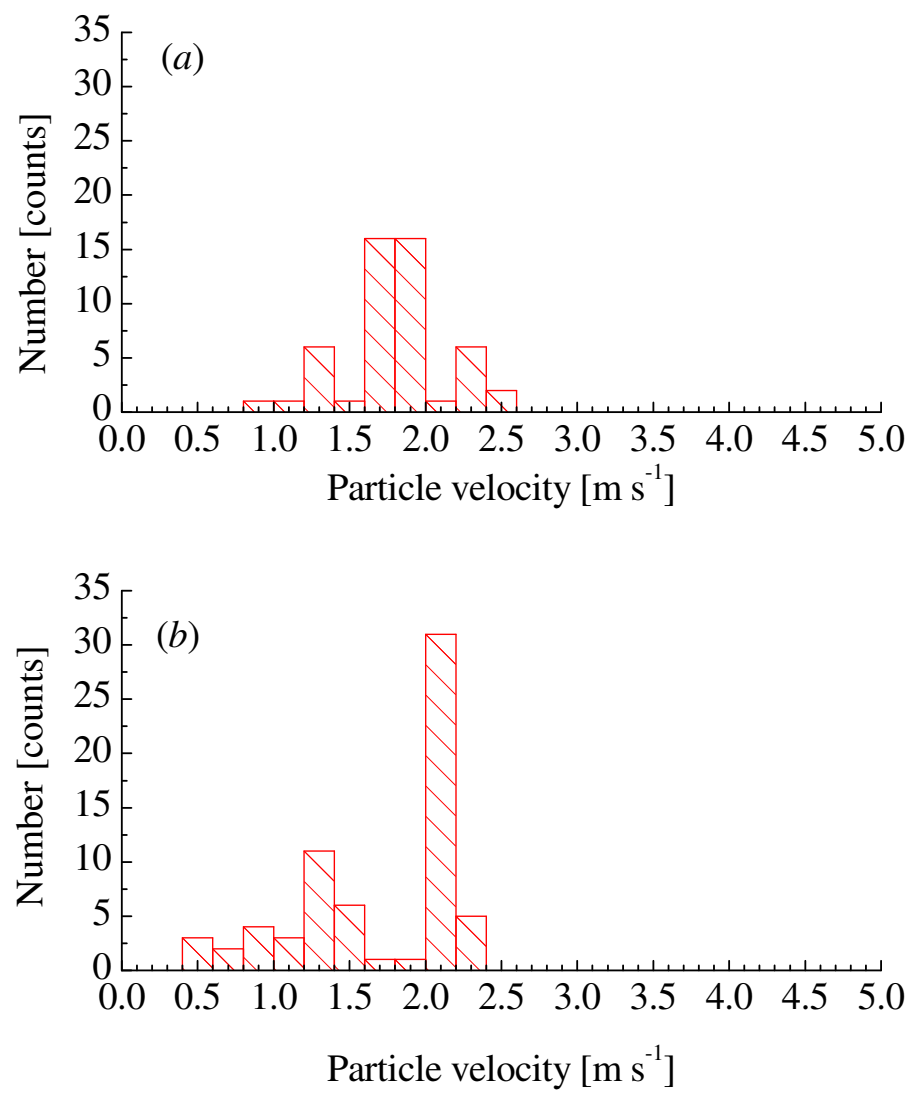

Figure 16. The experimentally measured and numerically calculated velocity distributions of injected PTFE particles into Ar thermal plasmas. The velocity distribution was estimated between the first and second coils of the plasma torch. (a) Experimentally measured (b) Numerically calculated 


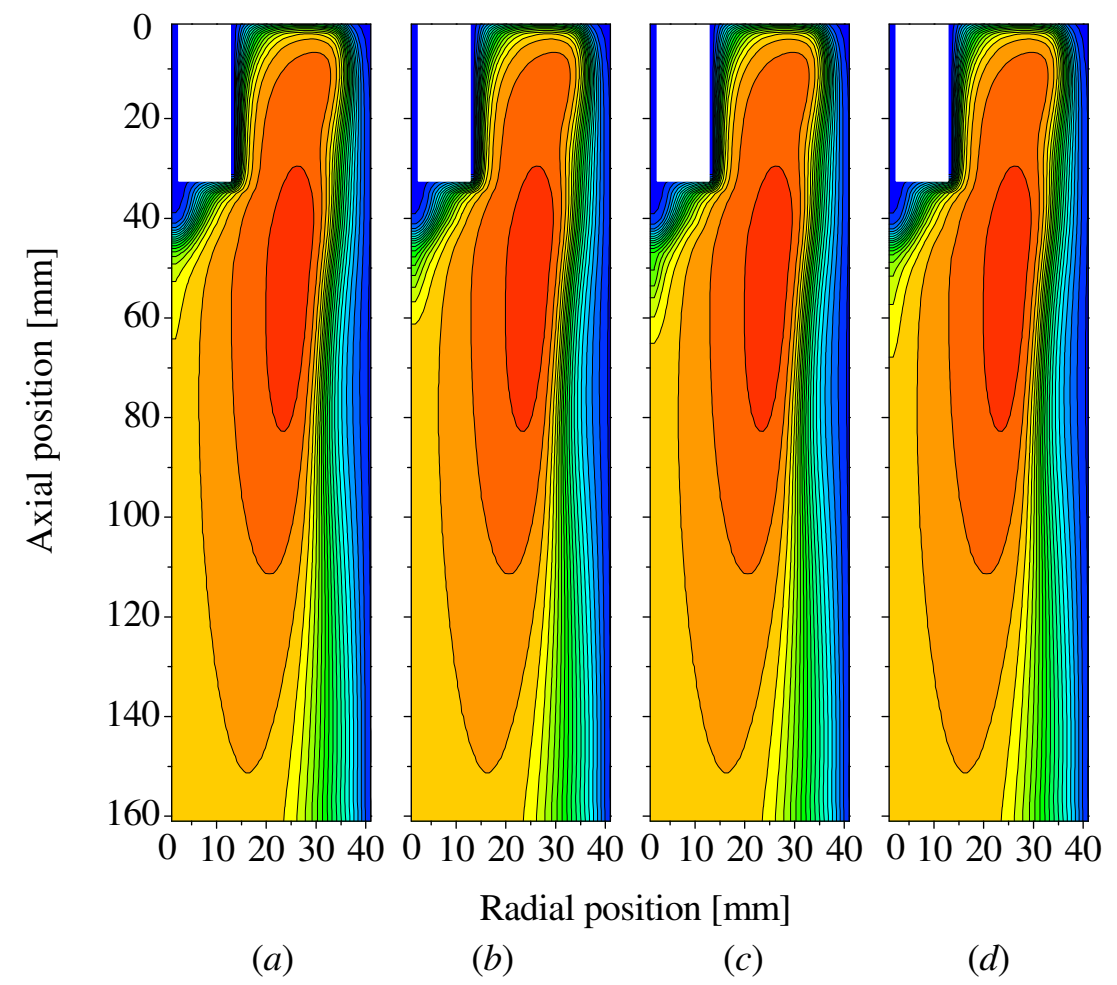

Figure 17. Temperature distribution of Ar thermal plasma with polymer solid powder injection. Thermodynamic and transport properties of Ar are used imaginarily for those of polymer-ablated vapours instead of their real polymer vapour properties. (a) PTFE; (b) PMMA; (c) PE; (d) POM. 


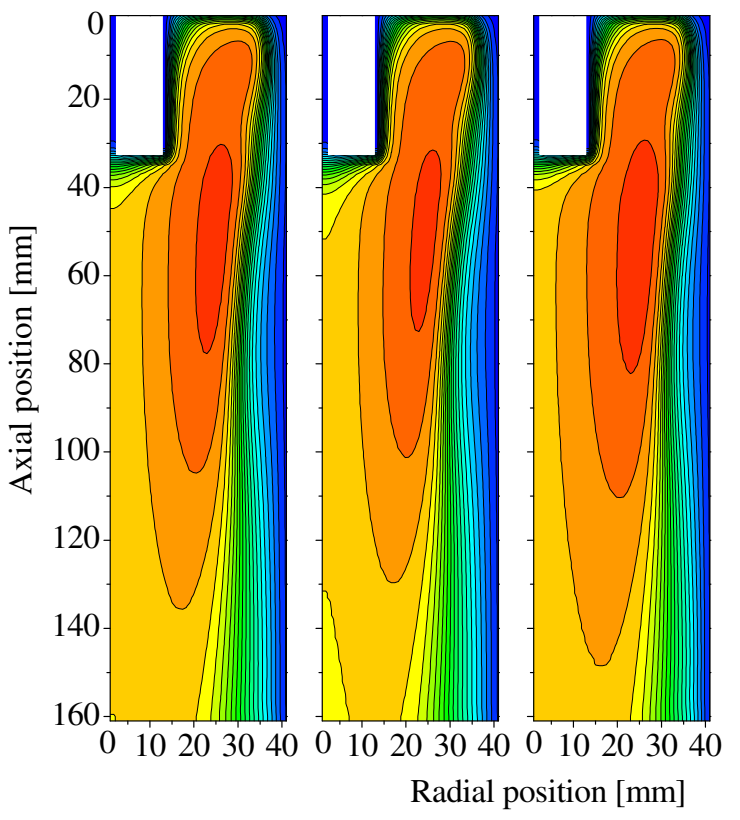

(a) (b)

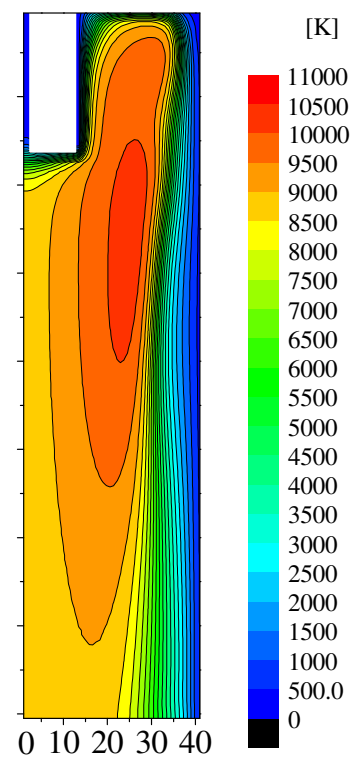

(d)

Figure 18. Temperature distribution of Ar thermal plasma with $0.1 \%$ premixed polymer-ablated vapour. No centre gas is fed. (a) PTFE (b) PMMA (c) PE (d) POM 